\title{
Development of a Photosynthetic Microbial Electrochemical Cell (PMEC) Reactor Coupled with Dark Fermentation of Organic Wastes: Medium Term Perspectives
}

\author{
Samir Bensaid *, Bernardo Ruggeri and Guido Saracco \\ Dipartimento di Scienza Applicata e Tecnologia, DISAT, Politecnico di Torino, \\ Corso Duca degli Abruzzi 24, 10129 Torino, Italy; E-Mails: bernardo.ruggeri@ polito.it (B.R.); \\ guido.saracco@polito.it (G.S.) \\ * Author to whom correspondence should be addressed; E-Mail: samir.bensaid@ polito.it; \\ Tel.: +39-011-090-4662; Fax: +39-011-090-4624.
}

Academic Editor: Haolin Tang

Received: 29 August 2014 / Accepted: 16 December 2014 / Published: 13 January 2015

\begin{abstract}
In this article the concept, the materials and the exploitation potential of a photosynthetic microbial electrochemical cell for the production of hydrogen driven by solar power are investigated. In a photosynthetic microbial electrochemical cell, which is based on photosynthetic microorganisms confined to an anode and heterotrophic bacteria confined to a cathode, water is split by bacteria hosted in the anode bioactive film. The generated electrons are conveyed through external "bio-appendages" developed by the bacteria to transparent nano-pillars made of indium tin oxide (ITO), Fluorine-doped tin oxide (FTO) or other conducting materials, and then transferred to the cathode. On the other hand, the generated protons diffuse to the cathode via a polymer electrolyte membrane, where they are reduced by the electrons by heterotrophic bacteria growing attached to a similar pillared structure as that envisaged for the anode and supplemented with a specific low cost substrate (e.g., organic waste, anaerobic digestion outlet). The generated oxygen is released to the atmosphere or stored, while the produced pure hydrogen leaves the electrode through the porous layers. In addition, the integration of the photosynthetic microbial electrochemical cell system with dark fermentation as acidogenic step of anaerobic digester, which is able to produce additional $\mathrm{H}_{2}$, and the use of microbial fuel cell, feed with the residues of dark fermentation (mainly volatile fatty acids), to produce the necessary extra-bias for the photosynthetic microbial electrochemical cell is here analyzed to reveal the potential benefits to this novel integrated technology.
\end{abstract}


Keywords: photosynthetic microbial electrochemical cell; dark fermentation; anaerobic digestion; microbial fuel cell

\section{The Concept}

Because of increasing interest in hydrogen as a renewable carrier of energy it was proposed that bacteria could be used to make this gas in an electrolysis-type process based on microbial fuel cells [1,2]. In such setup the electrons produced at the anode by the oxidation of simple organic compounds by electrogenic bacteria, are transferred to the cathode where they react with water to produce hydrogen. The microbe-assisted electrolytic system is capable of high $\mathrm{H}_{2}$ production efficiencies ranging from $67 \%$ to $91 \%$, depending on the substrate [3]. There are the reasons why research on hydrogen has been growing. Bio-hydrogen could satisfy three main conditions: (I) production and utilization with low impact on the environment $\left(\mathrm{H}_{2} \mathrm{O}\right.$ as a by-product after use); (II) it can be obtained from renewable energy resources (water, organic refuse and solar energy); (III) surplus can be stored and made available at specific times (e.g., when the amount of electric power requested is very high).

A photosynthetic microbial electrochemical cell (PMEC) for the production of hydrogen driven by solar power is based on photosynthetic microorganisms confined on to an anode and of heterotrophic bacteria confined to a cathode (Figure 1).

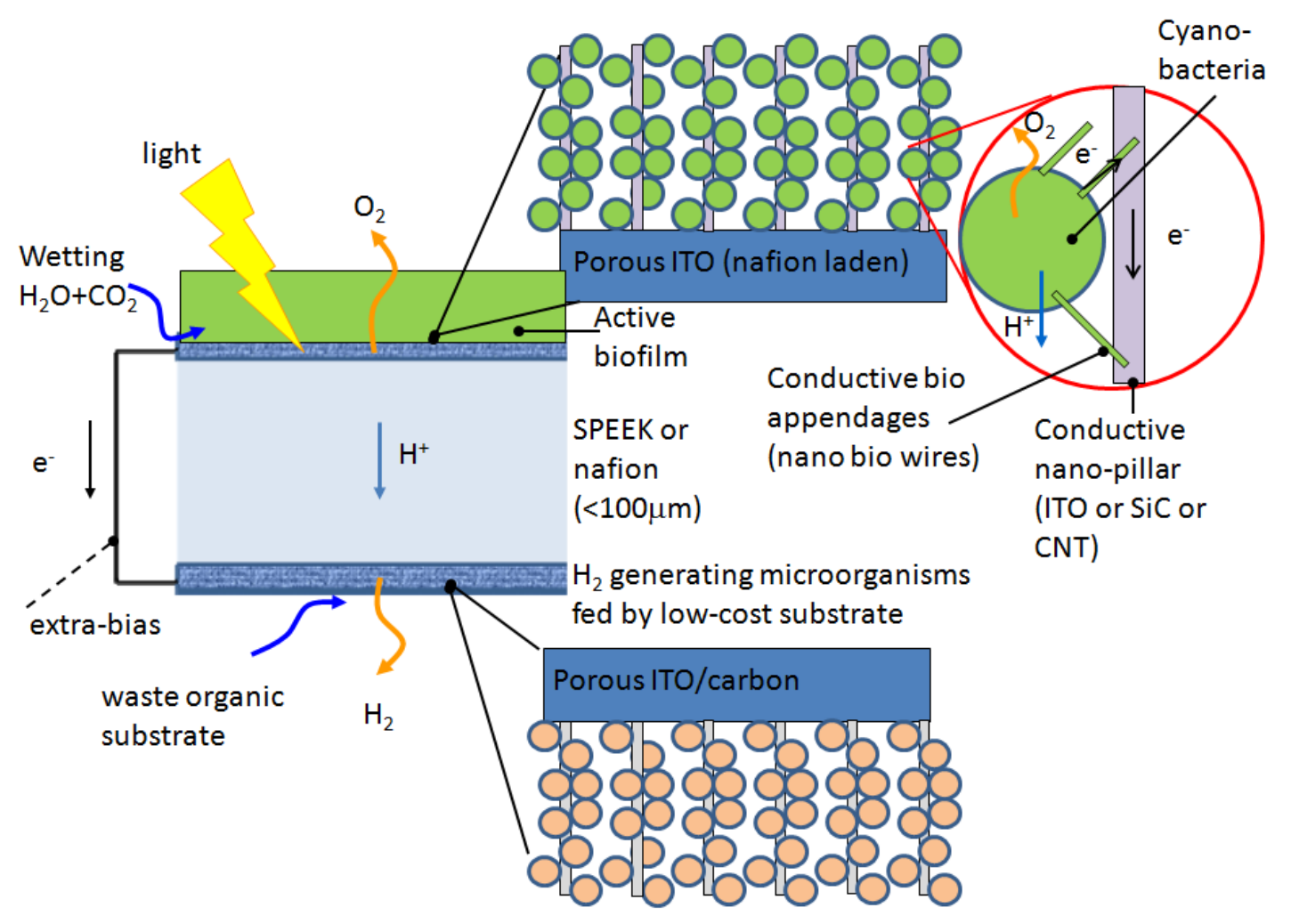

Figure 1. The photosynthetic microbial electrochemical cell (PMEC). 
Its basic operational characteristics are the following:

- water is split inside by cyanobacteria hosted in the bioactive film;

- the generated electrons are conveyed through external "bio-appendages" developed by the cyanobacteria to transparent nano-pillars made of indium tin oxide (ITO), Fluorine-doped tin oxide (FTO) or other conducting materials. The energised electrons are then transferred to the anodic electrode via a porous silicon carbide ( $\mathrm{SiC}$ ) and carbon nanotube (CNT) layer (Figure 1);

- the generated oxygen is released to the atmosphere;

- $\quad$ the generated protons diffuse to the cathode via a polymer electrolyte membrane (e.g., Nafion ${ }^{\circledR}$ or SPEEK);

- the protons are reduced by the electrons by ad hoc heterotrophic bacteria growing attached to a similar pillared structure as those envisaged for the anode and supplemented with a specific low cost substrate (e.g., organic waste, liquid outlet of a acidogenic step of anaerobic digestion;

- electrons flow through the electrodes via a connecting wire to which, if needed a small bias can be applied to foster proton reduction into hydrogen;

- the produced hydrogen will be pure and will leave the electrode through the porous layers.

In addition, the integration of the PMEC system with dark fermentation (DF) anaerobic digester, which is able to produce additional $\mathrm{H}_{2}$, and provides unique potential benefits to this integrated technology, which is here analyzed (Figure 2):

- the above device looks on one side like a photovoltaic panel where sunlight is captured by the cyanobacteria resulting in the other side (cathode side) which are in low or no light. Therefore locating the DF unit just underneath the panel is desirable;

- the dark fermentation outlet could provide, via e.g., a microbial fuel cell (see Figure 3), additional energised electrons for $\mathrm{H}_{2}$ production and will complement that generated in the PMEC bio-cathode [3];

- if a recirculation (possibly just driven by natural convection as in Figure 2) is ensured the heat required to boost anaerobic digestion could be derived from the heat generated by sun radiation and by joule effects at the PMEC. Alternatively, an independent heat transfer loop might be envisaged (see later Figure 3b). Such heat recovery may reduce the amount of methane (from a subsequent methanogenesis step) that has to be burned to keep the digester at about $35{ }^{\circ} \mathrm{C}$;

- via this recirculation the dark fermentation can also supply bacteria for the cathodic bacterial biofilm as well organic substrate to feed it (e.g., volatile fatty acids, VFA). As an alternative, a specific waste water feed line (domestic and/or from the agro-food industry) could be used and the organic load adjusted in order to feed the PMEC cathode, the outlet of the cathodic compartment could be sent to the dark fermenter for a fruitful heat and mass process integration;

- finally, the $\mathrm{CO}_{2}$ generated by the DF unit might be exploited to feed locally (if required) the cyanobacteria biofilm of the anode.

As depicted in Figure 3, an external bias can also be applied, by the application of a microbial fuel cell (MFC) over the DF outlet stream. 


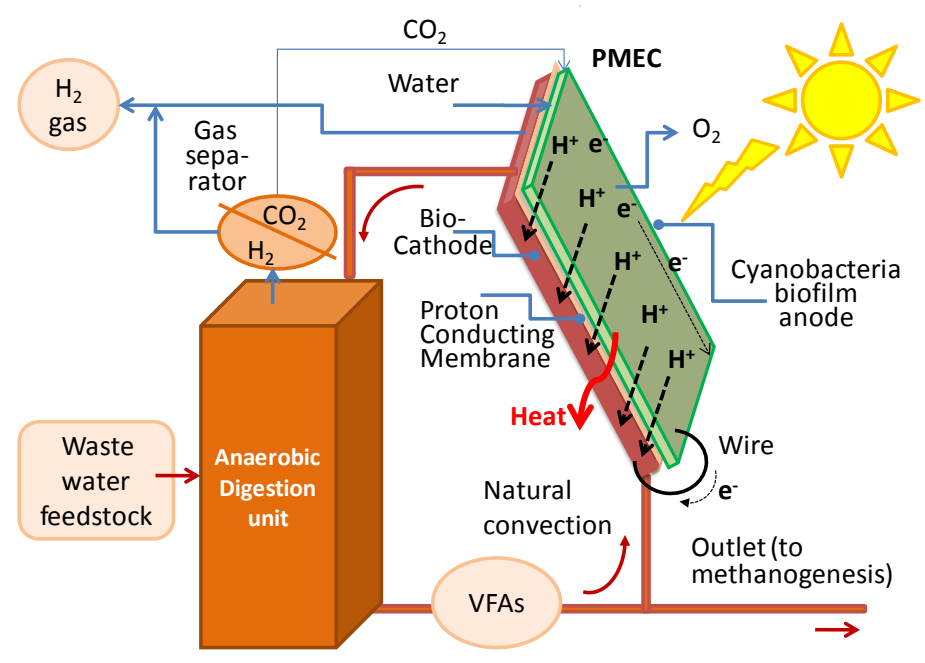

Figure 2. Integration of the PMEC photosynthetic microbial electrochemical cell with DF.

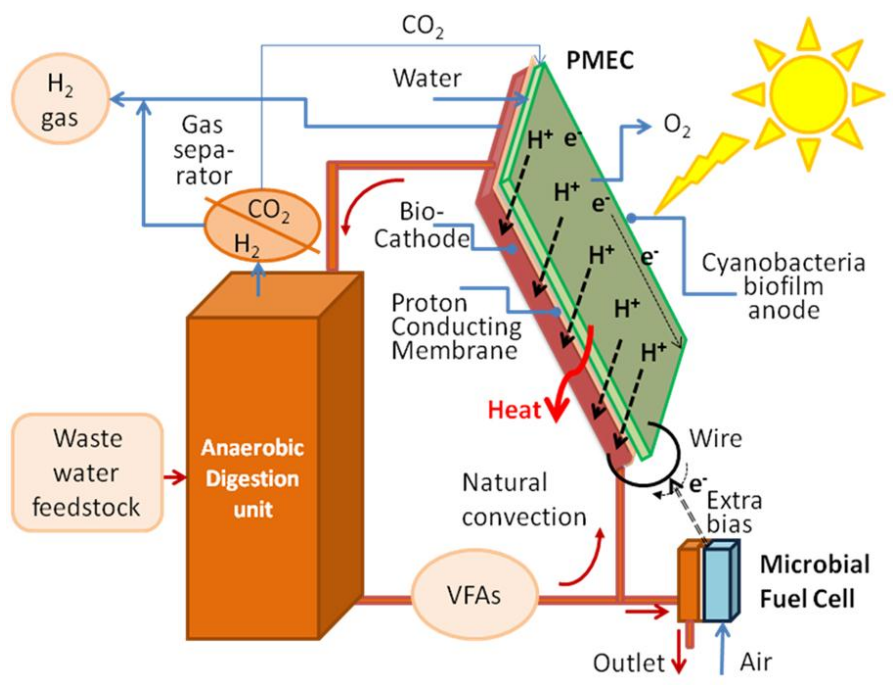

(a)

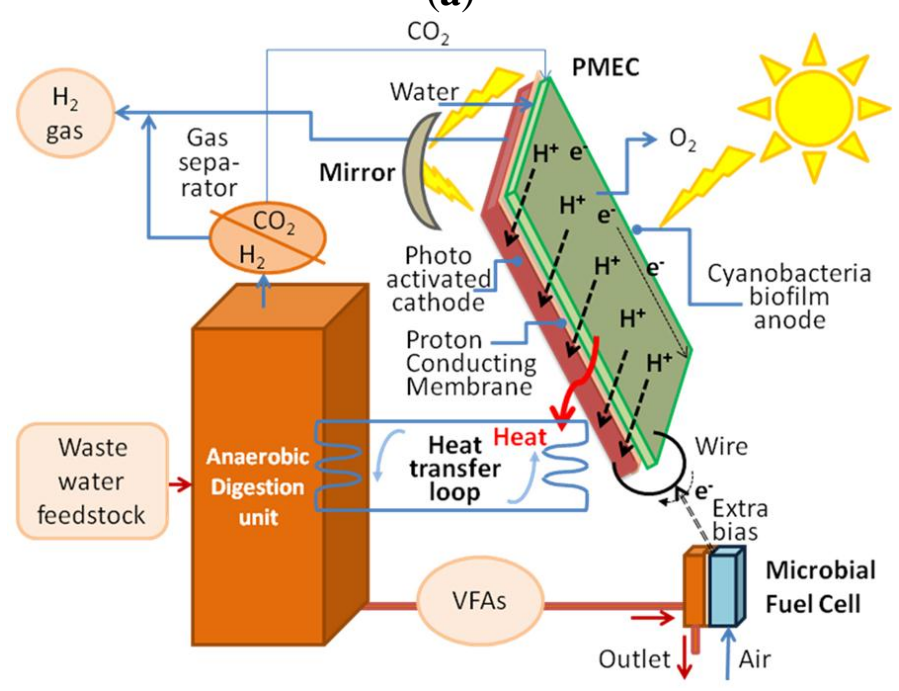

(b)

Figure 3. (a) Integration of the PMEC reactor with a DF unit applying an extra bias provided by a MFC operating on the outlet flow (b) integrated, if needed, by photochemical conversion at the anode induced by reflected light. 


\section{Photosynthetic Microbial Electrochemical Cell (PMEC)}

Hydrogen is a valuable energy carrier, an important feedstock to the chemical industry and useful in detoxifying a wide range of water pollutants [3]. Virtually all hydrogen is produced today by reforming fossil fuels but Nature has evolved elegant solutions to produce it in a more sustainable way (e.g., photosynthesis). Bio- $\mathrm{H}_{2}$ production has been deemed to be able to provide renewable and carbon-neutral alternatives for the production of hydrogen [3]. It can be achieved in three ways: photosynthesis, fermentation and microbial electrolysis cells, all technologies standing at the background of the PMEC technology. Both photosynthesis and fermentation suffer from low yields due to either oxygen sensitivity of the enzymes responsible for hydrogen production (hydrogenases) as in the case of photosynthesis or the existence of alternative metabolic routes for the reducing equivalents as in the case of fermentation. MFC, a candidate technology for wastewater treatment, have recently been applied to the task of hydrogen production. Nevertheless, due to energetic issues, hydrogen production cannot occur in this case without the help of an external power source [2].

The PMEC reactor aims at using photosynthetic microorganism at a bio-anode to provide protons and reducing equivalents from the light driven water splitting reaction to a bio-cathode where heterotrophic microorganisms uses them to produce hydrogen. This concept has the advantage of separating the oxygen evolving compartment from the hydrogen evolving one, thereby avoiding the issues of oxygen sensitivity. Also it can be designed and constructed to limit or avoid altogether the need for an external power source (Figure 4a). To achieve this, a multi-disciplinary approach is needed, where the engineering of the device is combined with the biological solution of both the metabolic and the extracellular electron transfer pathways (Figure 4b).

Electrons produced by the bacteria via the oxidation of energy rich organic substrates in a MFC are transferred to the anode and flow to the cathode linked by a conductive material containing a resistor or operated under a load [4]. The oxidisable substrate must be replenished either continuously or intermittently; otherwise, the device would act simply as a biobattery. Electrons are transferred from the bacteria to the anode either directly via membrane bound proteins or via "nanowires" [4]. In most MFCs the electrons that reach the cathode combine with protons (that diffuse from the anode through a separator) and with $\mathrm{O}_{2}$ (provided from air) producing water as the end product. The idea of using bacteria to generate electricity has been around for some time, but so far power production was very low and required the addition of exogenous mediators to shuttle electrons from the cell to the electrode surface [5].

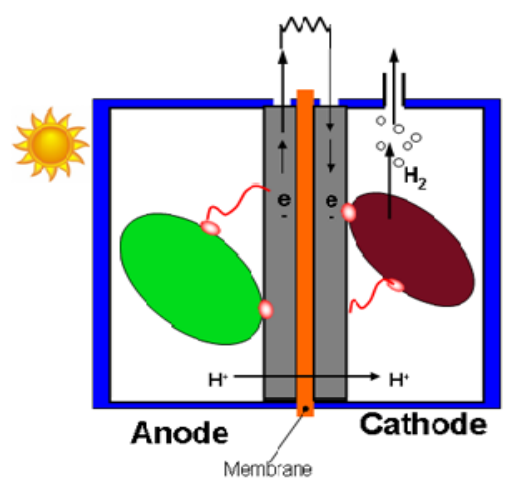

(a)

Figure 4. Cont. 


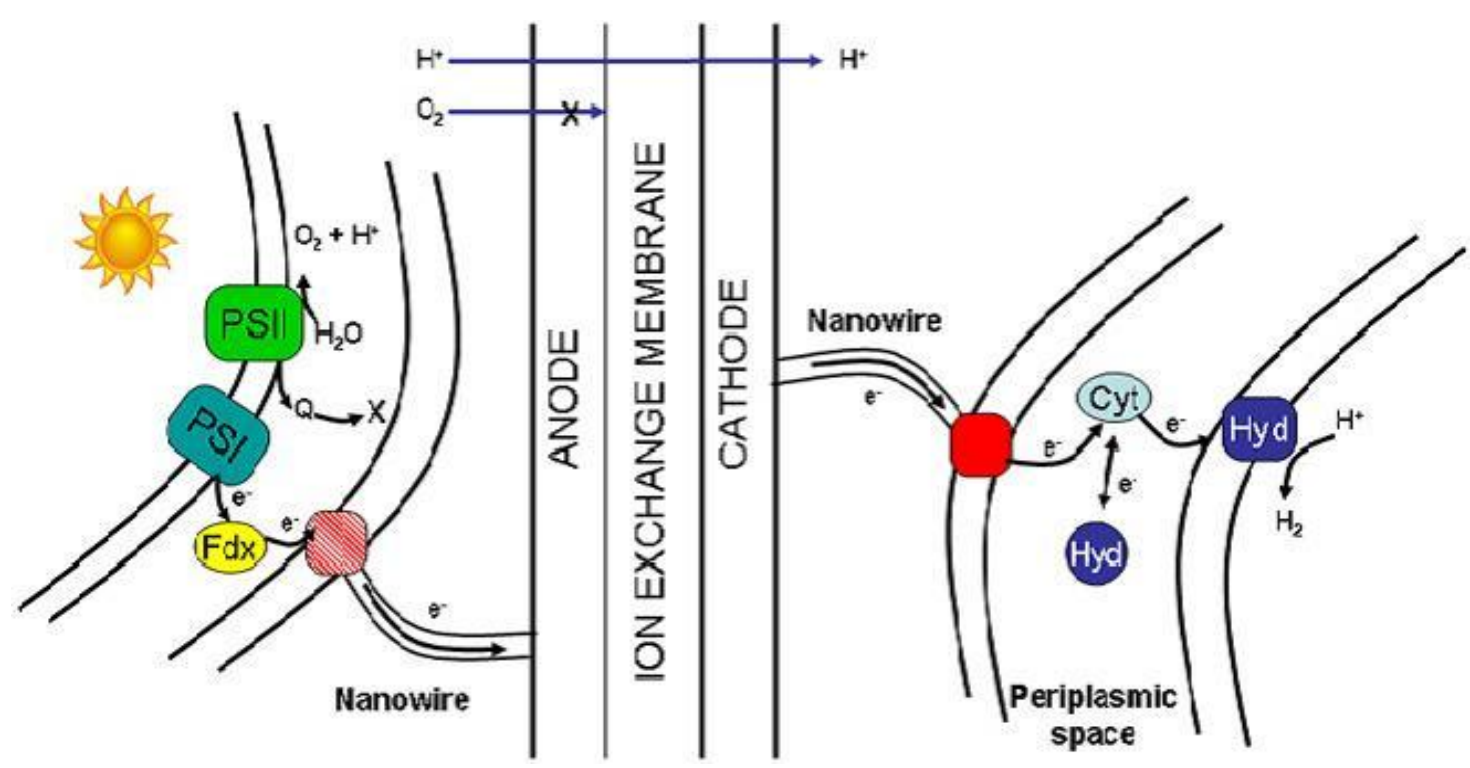

(b)

Figure 4. (a) Diagram of the PMEC. The cell is divided in two compartments by the ion-exchange membrane. The anodic and cathodic compartments contain the photosynthetic and heterotrophic microorganisms respectively. The electrical connectivity of the bacteria to the electrode is represented by the membrane bound proteins (red dot) and nanowires (red line); (b) Diagram representing a view of the bacteria/electrode interface. The red and pink squares represent the entry/exit point for the electrons while the cyan and yellow shapes represent the intermediate redox protein cytochrome Cyt-like in Desulfovibrio vulgaris bacteria or ferredoxin $(\mathrm{Fd})$ enzymes pool, respectively.

For example, in the last 10 years the power density has increased by five orders of magnitude to $27 \mathrm{~W} \cdot \mathrm{m}^{-3}[6]$. The increase in power density, though initiated by crucial advances on the biological side, has lately been almost exclusively driven by improvements on the engineering side, such as materials, cell architecture and buffers solutions, aimed at lowering the internal resistance [7].

The PMEC aims at using the Sun as the source of energy in a sort of photosynthetic microbial electrochemical cell. Beside electricity and hydrogen generation, an additional benefit of PMEC is that carbon dioxide is removed from the atmosphere by the integrated photosynthetic process [8]. The ability of photosynthetic microorganisms to produce electricity with metal electrocatalysis by using hydrogen producing photosynthetic organisms with an electrocatalytic anode was first reported in the 1960s [9]. This approach has also been exploited also in recent times where search for new materials for the metal electrocatalyst and reduction of the gas partial pressure have been the main target to improve the power output [10]. Another approach developed in the 1980s made use of externally provided redox mediators that facilitate the flow of electrons from the bacteria to the anode [11]. Though it has been proved to be efficient it also was shown to have two main drawbacks, the first being that the power output increases in the dark due to bacterial metabolism while oxygen production limits the output during illumination and second, and most importantly, that the added artificial redox mediators as external electron carriers are environmentally unsustainable [12]. In most of the other cases PMEC development led to the integration of the photosynthesis with the metabolism of heterotrophic bacteria. Organic matter can be accumulated by the photosynthetic process and subsequently oxidized by heterotrophic microbial fuel 
cells to produce electricity [12]. So far the most promising and interesting approach, one that make use of direct electron transfer between the photosynthetic microorganism and the electrode, has yet to be exploited successfully [13]. Direct electron transfer in photosynthetic organisms has not been fully demonstrated and characterized even though conductive nanowires have been described for the Cyanobacterium synechocystis spp. PCC 6803 [14] as shown in Figure 5. The fact that nanowires are produced in low $\mathrm{CO}_{2}$ concentration might be linked to the creation of alternative pathways used by the microorganism to dump the excess reducing equivalents produced by the photosynthetic reaction [15]. This factor needs to be taken into account when exploring conditions that facilitate the creation of electrical connectivity with the electrode. In addition, this may limit the potential of recycling the $\mathrm{CO}_{2}$ produced during anaerobic digestion to the bioanode hosting the cyanobacteria biofilm. Thus far, publications in which direct electron transfer was identified from the anode also included electrocatalysts, such as platinum or polyaniline, which are catalytically active for hydrogen produced by these photosynthetic microorganisms [10]. Very recently, the group of Baskakov recorded photocurrent on a carbon electrode coated with electrically conductive polypirrole using different species of cyanobacteria [16].
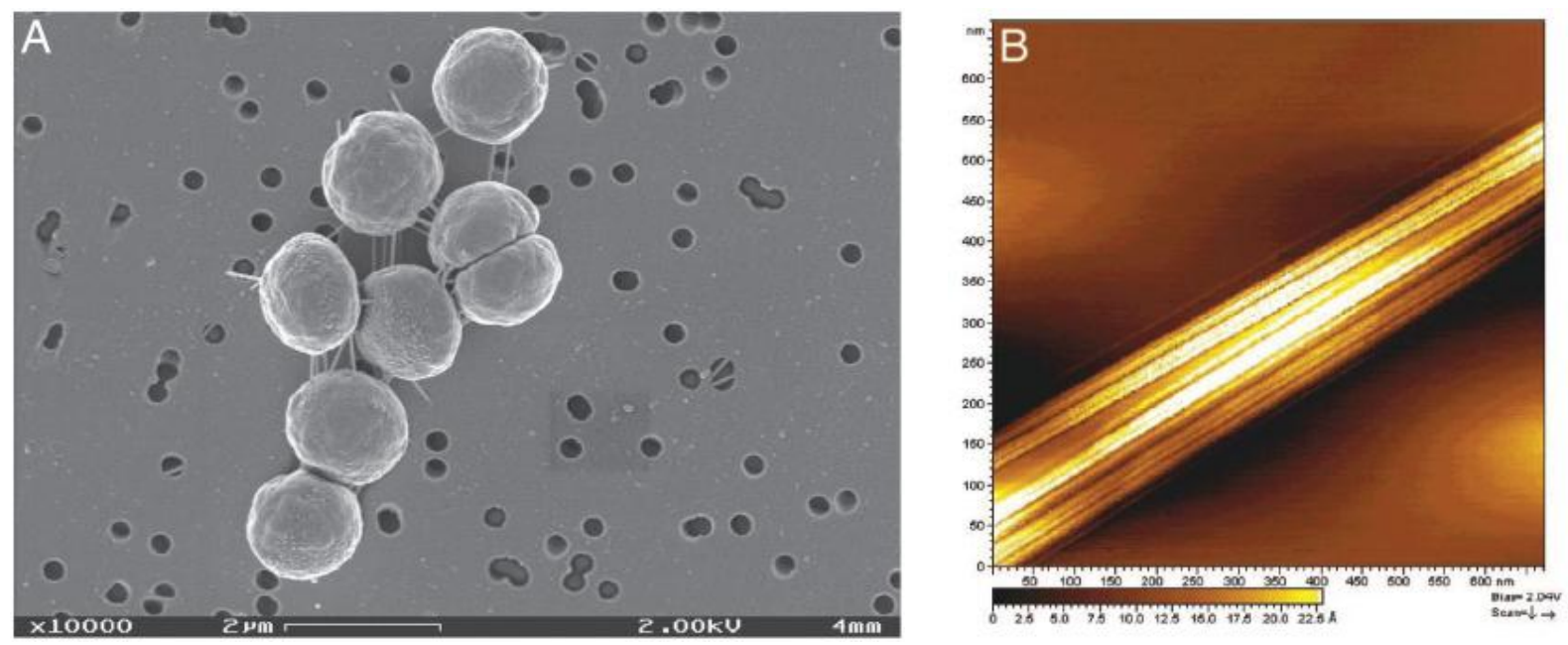

Figure 5. (A) Scanning electron microscopy (STM) image of Synechocystis strain PCC 6803 showing extracellular nanowires; (B) Scanning tunnelling microscopy image of one of the nanowires [14] (Copyright 2006, National Academy of Sciences, USA).

In this study the rate of current development upon illumination was higher than the rate of oxygen evolution, suggesting that the electrogenic activity is intrinsic to the microorganism on the electrode surface and that the source of electrons is the photosynthetic electron transfer chain. Furthermore, by using inhibitors the authors were able to pinpoint the source of the electrons showing that they are derived from photosystem II (PSII), although the mechanism of electron transfer remains unclear [16]. In the context of this finding, PSII from the cyanobacterium Thermosynechococcus elongatus was isolated and deposited on various electrode surfaces including titanium dioxide. In doing so, substantial photocurrents were recorded under optimized conditions. Despite this success, the intrinsic instability of the protein matrix of the isolated enzyme during the water splitting process makes this approach non-ideal for technological application. These observations sparked the idea of substituting the isolated PSII enzyme with the entire organism capable of self-repair and maintenance. Preliminary experiments have been performed by Barber's team to test the feasibility of the proposed approach [17]. Thermosynechococcus elongatus 
deposited on titanium dioxide electrodes forms biofilms (Figure 6). Using a three electrodes configuration where the working electrode is the anode, photocurrents were recorded as a function of illumination intensity and spectral quality as well as at different potential biases. Using red light to eliminate any potential contribution of the titanium dioxide a stable photocurrent was detected (Figure 6a). The sharp rise in current upon illumination is in keeping with that observed by Pisciotta [16] and collaborators and is an order of magnitude faster when compared to the rate of oxygen evolution suggesting that in the initial phase a mechanism of direct electron transfer from an electron rich metabolic pool (e.g., reduced quinones) is involved. The thermodynamic characterization of the produced photocurrent as a function of different applied potential biases, as well as in cyclic voltammetry (Figure 6b), indeed suggests that the electrons are derived from quinone pool. These are very promising preliminary results showing the electrogenic potential of intact photosynthetic organisms and the stability of the photocurrent generated.

(b)

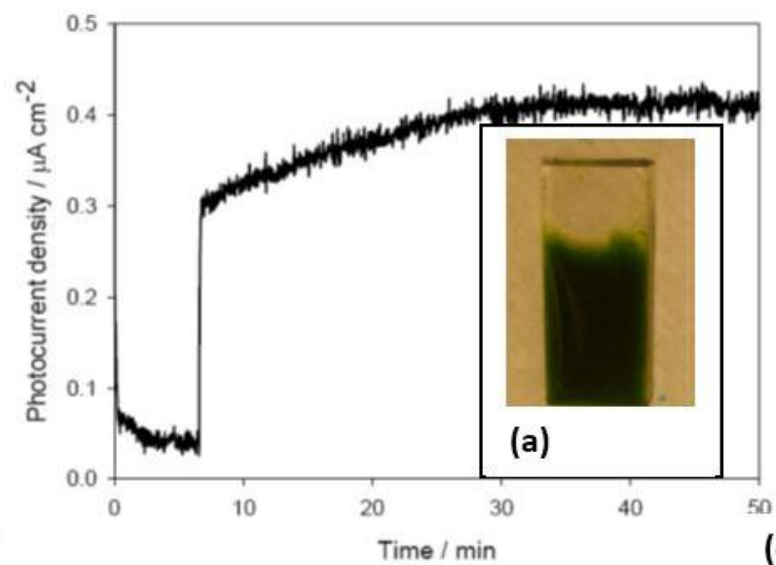

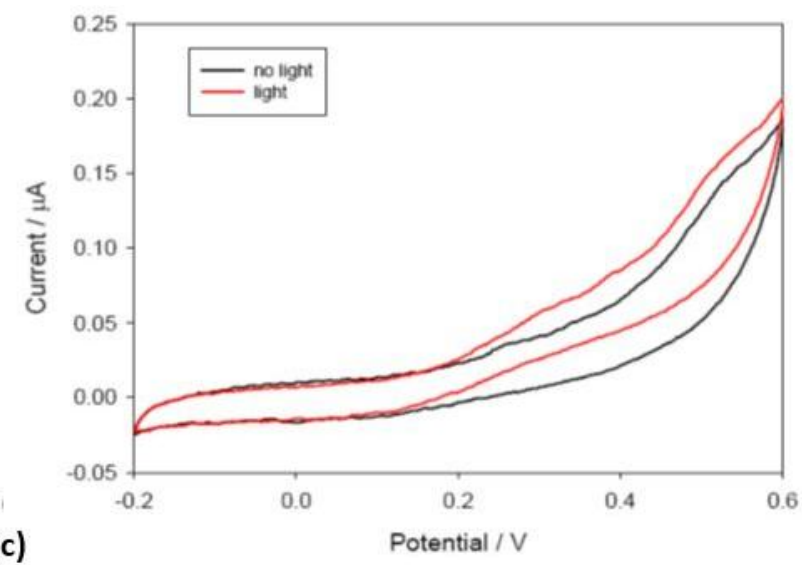

Figure 6. (a) Picture of the Thermosynechococcus elongatus biofilm on $\mathrm{TiO}_{2}$; (b) Photocurrent measured illuminating $T$. elongatus biofilm on $\mathrm{TiO}_{2}$ including a picture of the biofilm on $\mathrm{TiO}_{2}$. The rapid increase in current at minute 7 corresponds to the light being switched on; (c) Cyclic voltammetry recorded for the same electrode with (black line) and without (red line) illumination.

In PMEC the reaction carried out at the cathode defines the overall driving force and power output of the device in the same way as in conventional MFCs. In all cases oxygen reduction has been chosen due to the very positive reduction potential allowing maximum energy output [18]. However, in this case, the only output of the PMFC is electricity, raising question over overall efficiency. Instead, the flow of electrons from the anode to the cathode could be used to perform chemical reactions at the cathode leading to the production of molecules that could be used as fuel, such as hydrogen or methane. In this case, the device will be defined as a photosynthetic microbial electrochemical cell (PMEC) since fuel will be produced and not consumed. When the energy of the electrons is not high enough to carry out the chemical reaction at the cathode, a small amount of energy can be introduced from an external source.

So far all efforts involving photosynthetic organisms have been directed towards the generation of an electrical power. Only very few attempts have been made to combine bacterial metabolism with the production of either $\mathrm{H}_{2}$ or $\mathrm{CH}_{4}$ at the cathode and all involved the construction of microbial electrolysis cells where wastewaters and an external power source were used as fuel $[2,19]$. This makes the PMEC reactor technology particularly novel and challenging. 
In the PMEC system, the biocathode acts as "reducing agent" driving proton reduction to hydrogen. Previously, biocathode systems have been used for the catalysis of a range of conversions (reduction of oxygen, nitrate, perchlorate, as well as for the formation of hydrogen and methane) which emphasizes the capacity of certain microorganisms to take up the electrons from the electrode. Despite the increasing number of biocathode studies the mechanism of microbial electron uptake from electrode surfaces is still unknown [9]. A recent study involving gene expression and deletion analyses showed that genes for putative cell-electrode connections, such as outer-surface cytochromes and pilj, were not highly expressed in current consuming biofilms. Instead, bacteria-cathode interaction seemed to induce the over-expression of a monoheme c-type cytochrome [20]. These observations seem to suggest that a different mechanism is involved in electrons delivery and uptake to the electrode. Desulfovibrio vulgaris is often attributed a pivotal role in biocorrosion. It possesses a pool of c-type cytochromes which create a vast network of interconnected hems providing the electrical wiring for connecting multiple periplasmic enzymes [21]. Of these it was suggested that a high molecular weight cytochrome $\mathrm{Hmc}$ ) localized in the outer membrane is the entry point for the electrons which are redox coupled to a $[\mathrm{Fe}-\mathrm{Fe}]$-hydrogenase localized in the periplasm. Using membrane fractions, the presence of iron was found to be able to facilitate the production of hydrogen [10].

\section{Electrons Exchange}

The understanding of how microorganisms exchange electrons with electrodes has improved substantially and is expected to be helpful in optimizing practical applications of microbe-electrode interactions in the proposed PMEC system, as well as yielding insights into related natural environmental phenomena [22]. In contrast to the long history [23] of the study of direct microbial electron transfer to external acceptors (e.g., electrode surfaces), the history of direct electron flow in the opposite direction, i.e., from electrode surface to microorganisms, is rather short, with the first report appearing in 2004 [24]. An alternative to direct electron transfer is the possibility of redox active molecules functioning as electron shuttles, accepting electrons from electrodes and delivering the electrons to microorganisms so as to regulate fermentation patterns or promote the reduction of inorganic electron acceptors. However, a mediator-less microbial biocathode based on a naturally selected mixed culture or a high-efficiency pure culture would be much more desirable for the PMEC reactor. Several authors focus on the promising development of microbial biocathodes [19,24-27].

The important paper [24] focuses on using Geobacter species, since in the demonstration experiment the microbial community attached to the electrode was highly enriched in these bacterial species. Pure cultures of Geobacter metallireducens carried out an electrode-driven nitrate reduction while Geobacter sulfurreducens was not capable of facilitating this reaction, but could reduce fumarate to succinate using an electrode as the sole electron donor. In the original experiment the possibility of indirect electron transfer mediated by the reduction of protons to hydrogen followed by the consumption of hydrogen by the Geobacter spp. was ruled out because the electrode was poised at a potential that was too high for appreciable hydrogen production [26]. Also G. metallireducens is not able to use hydrogen as an electron donor, and a strain of $G$. sulfurreducens in which a gene for the hydrogenase required for hydrogen uptake had been deleted reduced fumarate as well as wild-type cells [24,27,28]. 
The presence in the genome of G. sulfurreducens of four hydrogenases (putatively two in the cytoplasm and two periplasmically oriented membrane bound) has suggested the exploitation of this bacterium for electrode assisted hydrogen production in microbial electrolysis cell (MEC) supported by acetate [29]. The same approach was also proposed for geobacter mixed cultures [30]. Nonetheless, G. sulfurreducens does not represent one of the best hydrogen producers among bacteria, and at least one of the membrane-bound hydrogenases is responsible for hydrogen uptake by G. sulfurreducens, therefore it is not optimized for hydrogen production but for the reverse reaction.

Most hydrogenases are reported to work very close to the thermodynamic potential for $\mathrm{H}_{2}$ production [31]. Thus, if electrons enter the metabolism directly at the hydrogenase level (at mediator less $\mathrm{H}_{2}$-producing biocathodes), no energy is likely to be gained by the microorganisms. Energy can only be gained if electrons enter the metabolism at the level of a sufficiently more electronegative component, such as an outer membrane cytochrome. Growth with an electrode serving as an electron donor is theoretically possible when common electron acceptors are reduced on the inner side of the inner membrane or in the cytoplasm. This is because the reduction of these electron acceptors consumes protons for the production of the reduced end product. Consumption of protons within the cytoplasm will result in a proton gradient across the inner membrane (Figure 7a, from [19]).

The mechanisms for electron exchange between electrodes and Geobacter species have also been proposed for the bioanode, while the mechanisms employed for the electron uptake at the cathode have not been studied so far, even if the first assumption is that similar mechanisms are used as for transfer to an electrode, albeit in opposite direction. Nonetheless, when G. sulfurreducens oxidizes acetate with electron transfer to electrodes it forms thick $(>50 \mu \mathrm{m})$ biofilms and even cells at this substantial distance from the anode are considered to contribute to the electrical current production [32,33]. The working model for electron transfer to the anode in thick G. sulfurreducens biofilms seems to involve conductive pilj [34]. Apparently these pill can facilitate electron transfer through the bulk of the biofilm [32,33], but (see Figure 7) cytochromes on the outer surface of the bacterium [34,35] are required to facilitate electron transfer between the biofilm and the electrode surface [36]. However, current-consuming fumarate-reducing biofilms of Geobacter species are much thinner than current-producing biofilms [20]. Gene expression patterns in current-consuming cells are very different than those in current-producing cells and deletion of genes that are essential for current production do not impact on current consumption and vice versa [37]. These results suggest that the routes for electron transfer from electrodes to cells may be different than those for current production. The formation of biofilm plays an important role in the generation of electrode potential [38] and it is becoming clear that a correlation exists between the molecular basis underpinning the biofilm formation and the direct transfer of electrons from/to the electrode to/from the bacterial cells. Type IV pilj and $C c p A$ protein were demonstrated to be needed for biofilm formation in Clostridium strains [39]. The same type IV pilj were suggested to have a key role for both homogeneous electron transfer (through the biofilm bulk) and heterogeneous electron transfer (across the biofilm/electrode interface) by cyclic voltammetry on biofilms of wild type and mutant G. sulfurreducens strains on graphite electrodes [40]. 
A
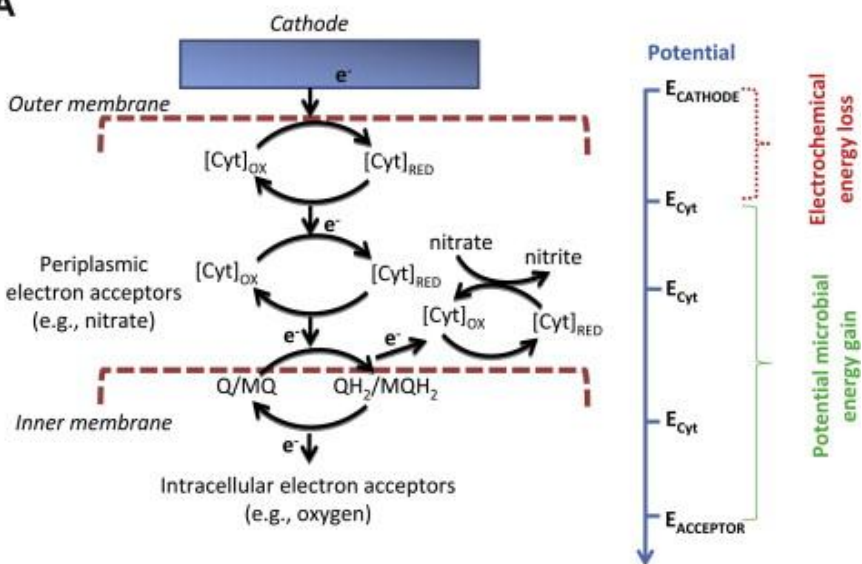

B
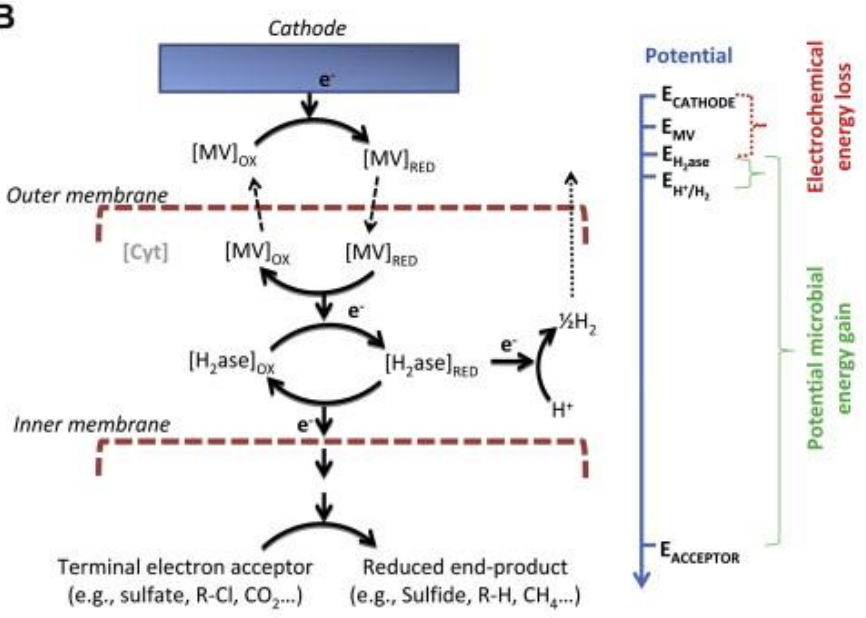

C

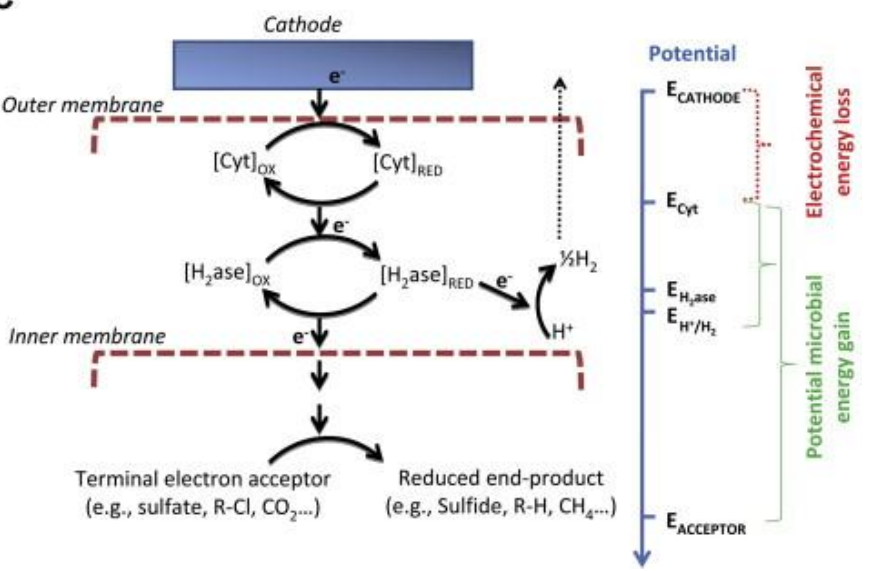

Figure 7. Proposed mechanism for hydrogen production and energy conservation coupled to proton translocation in microbial cells at the biocathode. Legend: $E c h=$ energy-conserving hydrogenase; $h y d=$ hydrogenase. (A) Direct electron transfer involving cytochrome-hydrogenase partnerships; (B) Indirect electron transfer with external redox mediator; (C) Direct electron transfer with internal redox mediator. In the three mechanisms the potential microbial energy as well as the electrochemical energy loss is different [10].

Several high efficiency hydrogen-producing Clostridia were observed to be able to rapidly produce biofilms which can stably interact through this "bio-glue" to a supporting material which could be exploited for the development of efficient biocathodes [41]. The best performing bacterial hydrogenases studied so far are produced by Clostridia such as Clostridium acetobutylicum and C. pasteurianum. 
The concept of electron connectivity through bacterial produced nanotubes has been extended to intercellular nanotubes, facilitating cytoplasmic exchange (but potentially also charge transfer and networking to electrodes) between Bacillus subtilis and Staphylococcus aureus or Escherichia coli [42]. An appropriate term for such structures may be interspecies nanotubes [43]. This extends to well-known laboratory used strains (E. coli) the possibility of being employed as strains for targeted application in biocathode and bioanode development needed for the PMEC technology.

In addition to the above-cited application of G. sulfurreducens for hydrogen production in microbial electrolysis cells, microbial biocathode concepts that were developed so far for catalyzing cathodic hydrogen production were based on an immobilized pure culture of Desulfovibrio vulgaris [44] with methyl viologen as a redox mediator. A microbial biocathode for hydrogen production was described by Rozendal: this has been shown to operate for up to $2000 \mathrm{~h}$ and it was based on a selected mixed culture of electrochemically active micro-organisms, forming biofilm layers on the surface of graphite felt electrodes [45]. Other reports propose the employment of microbial electrolysis cells for optimal hydrogen production by exploiting the residual organic compounds present in dark fermentation effluent [2] or by employing hydrogenophilic dechlorinating bacteria [46].

\section{Energy Loss}

A key goal for the PMEC technology, especially if the more aggressive process option is considered with no additional bias applied (Figure 2), will be the minimization of energy losses in order to achieve maximum efficiency. The total internal resistance $\left(R_{i n t}\right)$ of a MFC depends of many terms: the anodic resistance $R_{a}$, the cathodic resistances $R_{c}$, the ions exchange membrane resistance $R_{m}$ and electrolyte resistance $R_{e}$. As it is well known [47], only in the ohmic region when a linear variation of the voltage $v s$. current occurs it is possible to assert that either activation or diffusive losses are negligible at the electrode. These energy losses are associated with both the anode and the cathode materials in term of ruggedness able to establish the adhesion of the biofilm and, and to the concentration gradients of reactants as well as products in it, and the loss in electrical potential during extracellular electron transfer [48]. Proton gradients across the proton exchange membrane could generate significant energy losses per $\mathrm{pH}$ unit while energy loss in extracellular electron transfer results mainly from the resistance of the biofilm hence from its compactness. Thus, the number and nature of the steps in the pathways of electron transfer are also important factors that need to be taken into account. The reduction potential for hydrogen formation at the cathode is $-0.41 \mathrm{~V}$ (at pH 7 and 1 bar of hydrogen partial pressure) therefore, the potential of the electrons at the anode is crucial to determine the feasibility of the reaction to occur. At the anode the two photosynthetic reaction centers of the cyanobacteria can potentially provide electrons with very different energy [49]. The quinone of PSII will not have enough energy to drive the hydrogen formation at the cathode. This said, photosystem I (PSI) which is redox coupled to PSII, is capable of providing electrons with sufficient energy as reduced ferredoxin. This terminal electron acceptor of PSI has a reduction potential that is more negative than the one for hydrogen formation. Therefore, it is crucial, in order to minimize energy losses, those electrons are collected at PSI/ferredoxin level. The efficiency will be slightly lower due to the necessity of more photons to activate the electrons at the level of PSI but the energy gain will be largely compensated. Energy losses caused by electrical resistance of the counter-ion transfers in the membrane and liquid medium for charge neutrality are classified as holmic losses. They are strongly 
dependent on distance between the electrodes, resistivity of electrolytes and current density [48]. As previously stated the attention of the scientific community has been focused on tackling engineering issues in MFC design and therefore the source of energy loss are well understood in terms of ohmic losses $[4,48]$. One of the main goals of PMEC proposed technology will be to characterize and tackle the energy losses associated with extracellular electron transfer and thus understand the influence that different intracellular pathways play on the metabolism. In order to construct a competitive and efficient device the energy losses will have to be minimized. Substantial improvements could arrive from cell selection architecture and assembly of PMEC. Such advances usually occur as a gradual evolution towards the two chamber scheme in Figure 1. When oxygen is the final electron acceptor, as is the case in systems devoted to the production of electric power, the selection of microorganisms led to the development of air-cathodes, with the basic rationale of exposing the cathode directly to air, eliminating limitations in oxygen supply to the electrode due to mass transfer issues [4]. Further refinements, mostly due to Logan and co-workers, tackled the internal resistance attempting to lower it by bonding the anode and the cathode together via the electrolyte membrane and lately by eliminating the electrolyte membrane altogether. These improvements on the design are mostly responsible for the observed increased efficiency [4]. More recently, efforts have been focusing on the optimization of the mass transport and fluid circulation with improvements in the Coulombic efficiency [50]. Nevertheless, it has to be born in mind that flow and stirring systems carry several drawbacks such as excessive growth of the biofilm and the fact that the energy necessary for moving the fluid has to be taken into account in the overall efficiency of the system. Planar electrode configurations have been the choice but other architectures have been investigated some of which offer potential advantages for scalability and exposed surface [4]. Independently of the selected architecture a parametric optimization of the geometry can lead to major improvements and drive the cost down. Several groups have investigated the optimization of the relative surface areas of the components anode-membrane-cathode with particular attention to the increase in internal resistance when the membrane is too small [51].

There are at least three possible reasons why microorganisms use extracellular electron transfer, which can be harnessed at an electrode surface. The first and best studied is cell respiration using solid metal oxides, such as iron. Secondly, it is possible that cells can transfer electrons directly to another cell without the need of intermediates such as hydrogen. Thirdly, there is a possibility not yet explored, relating to the potential role of electron transfer in cell-cell communication [52]. Research on the mechanism of electron transfer by electrochemically active bacteria has mainly focused on the anode of microbial fuel cells (examples of anode respiring bacteria are from genera Geobacter, Shewanella, Pseudomonas, Clsotridium, Desulfovibrio, Escherichia and Klebsiella). Geobacter sulfurreducens cannot reduce Fe (III) oxides without direct contact. Direct electron transfer involves outer membrane c-type cytochromes $O m c B$, $O m c E, O m c S$ and $O m c Z$, multi-copper proteins $(O m p B$ and $O m p C)$ and pilj (pilA-pilD). The genes were shown to be up regulated in thick current producing biofilms as shown in Figure 8 [25,32,34,40,52-54]. Voltammetric methods have been used to detect multiple redox-active species [54] while mutants lacking the genes pilA and $O m c Z$ produced considerably less current and thinner biofilm [40]. Nevertheless, controversy still remains on the electrons pathways as other studies have shown that deletion of $O m c Z$ and pilA does not reduce the electron transfer capability suggesting that the pilj are involved in long range electron transfer within thick biofilms while membrane bound proteins play a role in the electron transfer from the cell to the metal surface [34]. On the other hand it has been shown that a G. sulfurreducens 
which showed enhanced current production had substantially more pilj but contained less c-type outer-membrane cytochromes [55]. The other well studied metal oxide reducing bacteria, Shewanella spp., also showed the involvement of outer surface c-type cytochromes (OmcA and $M \operatorname{trC})$ and other proteins as well as pili structures [56-58]. Also in this case deletion of the genes OmcA and $M t r C$ lead to the production of nanowires that appear to be non-conductive, based on scanning electron microscopy (STM) experiments, resulting into an $85 \%$ decrease in current production $[57,58]$. These bacterial pilj capable of transferring electrons are often also called "nanowires". Evidence to support the possibility of cell respiration using these uninsulated nanowires was initially based on measurements of electrical conductivity in the $\mathrm{z}$ plane. It was then shown that nanowires produced by Shewanella oneidensis MR-1, arrayed in large bundles reaching $50 \mathrm{~nm}$ in diameter and extending to several micron from the producing cells, also exhibited non-linear electrical transport properties along their length [59]. Experiments with gold-labelled antibodies have shown that these highly conductive nanowires are decorated with proteins including some of the major decaheme cytochrome, generally involved in iron oxide reduction. Bacterial cells containing deletion mutations in the gene pilD do not produce nanowires and are incapable of electricity production [14].

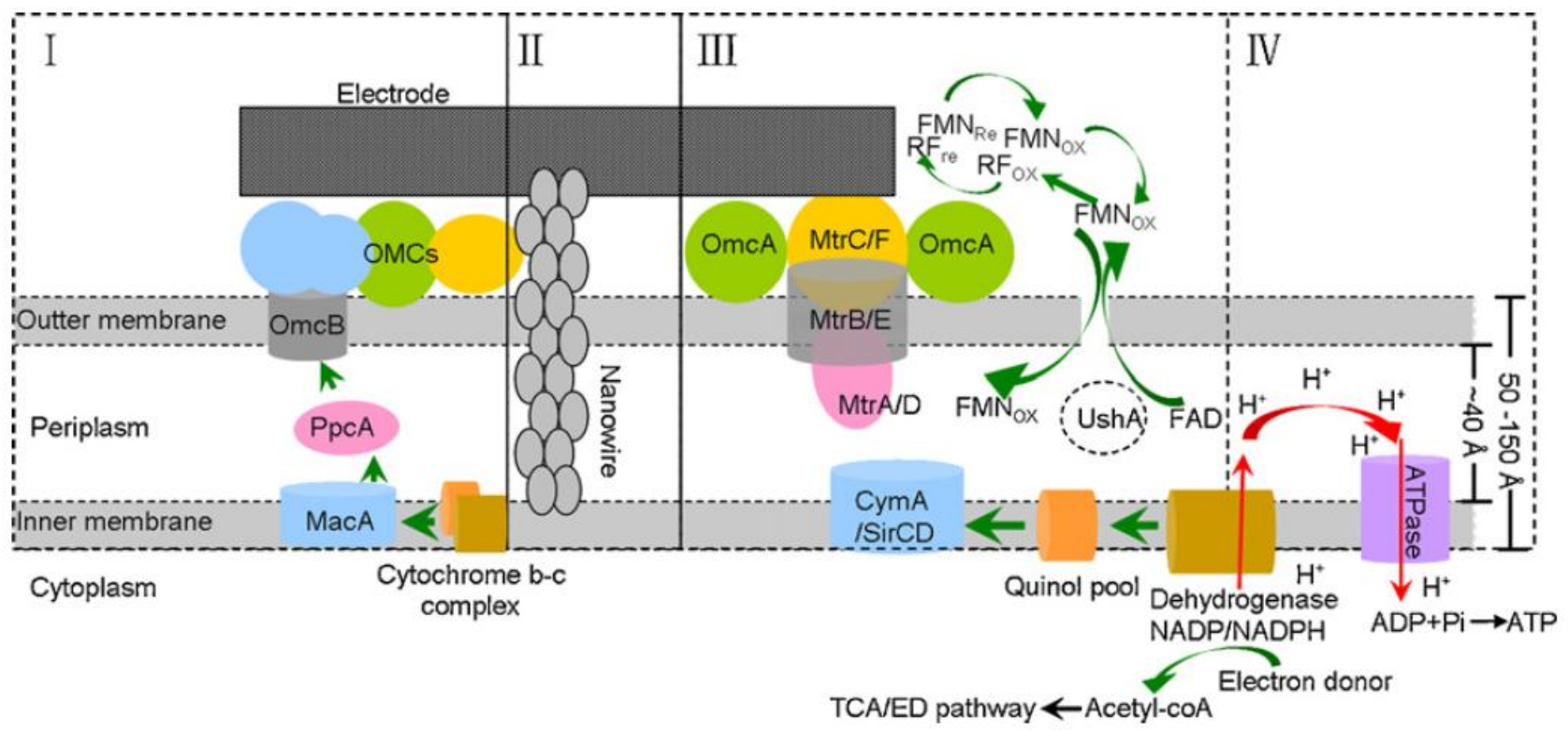

Figure 8. Extracellular electron transfer model of Geobacter and Shewanella. (I) The OMC-based direct electron transfer conduit in Geobacter; (II) bacterial nanowire; (III) electron transfer network of Shewanella including flavins and CTCs; (IV) electrode respiration-coupled proton motive force and energy (ATP) generation [53].

Shewanella spp. also produces flavins as soluble redox mediators leading to contrasting views on the mechanism of extracellular electron transfer. However, a recent study indicated that $\mathrm{OmcA}$ and $\mathrm{MtrC}$ mediate the reduction of flavins suggesting that there might be no clear distinction between the electron transfer mechanisms but rather a finely tuned integration of pathways [57]. Harnessing the power of microorganisms at an electrode requires that the electrons are conveyed to the surface and thus the packing of the microorganisms on the surface and the amount of available surface area are important factors. It has been shown that high power densities are attained based on projected surface areas supporting the 
evidence that certain bacteria, such as G. sulfurreducens, are capable of maintaining activity across thick biofilm [1]. Under these conditions, pilj production is essential for optimum current production. It remains to be determined whether the microbial nanowires must directly contact the anode or whether cell-to-cell electron transfer is possible through the biofilm.

Another mechanism for long-range electron transfer in thick biofilms might involve mediators produced by the microorganisms [52]. The critical issue with mediated electron transfer is the diffusion of the shuttle out of the biofilm or the bacterial environment. As the energy invested to produce the mediator is considerable, this efflux can render the shuttling process thermodynamically inefficient. Use of a mobile redox mediator should be therefore discouraged in favor of direct mechanisms that also have the advantage of allowing specific pathway tuning. It is interesting to point out that the highest power densities microbial fuel cells are almost always produced inoculating the anode with a rich and diverse source of bacteria [52]. This might be associated to the cooperative combination of the metabolic pathways but it might also be partly due to the synergistic interaction of different electron transfer pathways where the nanowires produced by one species are also used by others. Last but not least, the key challenge of the PMEC reactor is to modify microbial metabolism for optimal hydrogen production.

\section{Materials for PMEC}

Electrode materials must be conductive, biocompatible, and chemically stable in the reactor solution. The most versatile material is carbon, available as compact graphite (plates, rods, granules), as fibrous material (felt, cloth, paper, fibers, foam), as glassy carbon and as polymeric ink. As the electrical current increases with the overall internal surface area, then the use of materials with high surface area is preferred following the general order: carbon fibers > carbon foam > graphite [4]. Substantially higher surface area is achieved by using reticulated vitreous carbon, available in different pore sizes [60]. To increase the electrode performance, chemical and physical modifications have been attempted. For example nanostructured polypyrrole was deposited on carbon paint to improve the efficiency of electron harvesting from photosynthetic biofilms [16] while heat treatment in an ammonia atmosphere increases oxygen reduction at abiotic cathodes [4]. In the Authors' experience, oxygen plasma treatment increases the efficiency of adhesion and electron harvesting from biofilms. In this system, the requirements for the anode and the cathode might be different as direct electron transfer may be affected by the nature of the material chosen. Furthermore, as the reaction at the anode is light dependent, transparency of the electrode can play a crucial role for increasing the amount of active cells. The few examples in the literature of photosynthetic microbial fuel cells rely on the use of carbon-based electrodes. Conversely, the promising results showed in the previous section involved biofilms of T. elongatus on titanium dioxide. The porosity of the material can be controlled with the particle size and by using nanorods, which will be the primary option to be pursued. Vertically oriented pillar structures could be constructed on the micrometer scale which will greatly increasing the surface area while maintaining a degree of transparency. Other nanomaterials such as nanotubes have been shown to improve the interaction with microorganisms [61] and graphene has just recently been used to interface bacteria [62]. In the PMEC technology, the Authors' expertise gained at DISAT of Politecnico di Torino may exploit the expertise gained in recent years in the assembling of nanostructured electrodes based on nanopillars (Figure 9). 
Proton exchange membrane optimization will also be crucial; in fact, in fuel cells it provides the separation between the fuel and the oxidizing agent and at the same time allows for transport of positive charges to compensate for the electron transport. Polymer electrolyte membranes attracted large interest since they deliver high power density while operating at relatively low temperature and Nafion ${ }^{\circledR}$ has set the industry standard. Nafion ${ }^{\circledR}$ consists of hydrophobic fluorocarbon backbone, inert in both oxidizing and reducing atmosphere, to which sulfonic groups are attached giving the property of high proton conductivity [63].

Even though Nafion ${ }^{\circledR}$ has been widely investigated for MFC applications its use is strongly affected by its oxygen permeability. Currently, polyether ether ketone (PEEK) is demonstrating to be a promising alternative thanks to its low-cost, thermal and mechanical stability, tunable proton conductivity by means of sulfonation and low oxygen permeability (one order of magnitude lower than Nafion ${ }^{\circledR}$ ) due to the narrow separation between hydrophobic and hydrophilic domains [64,65]. As previously discussed, the generation of a proton gradient and the formation of a constant flow are fundamental for the maintenance of a high Coulomb efficiency [66].
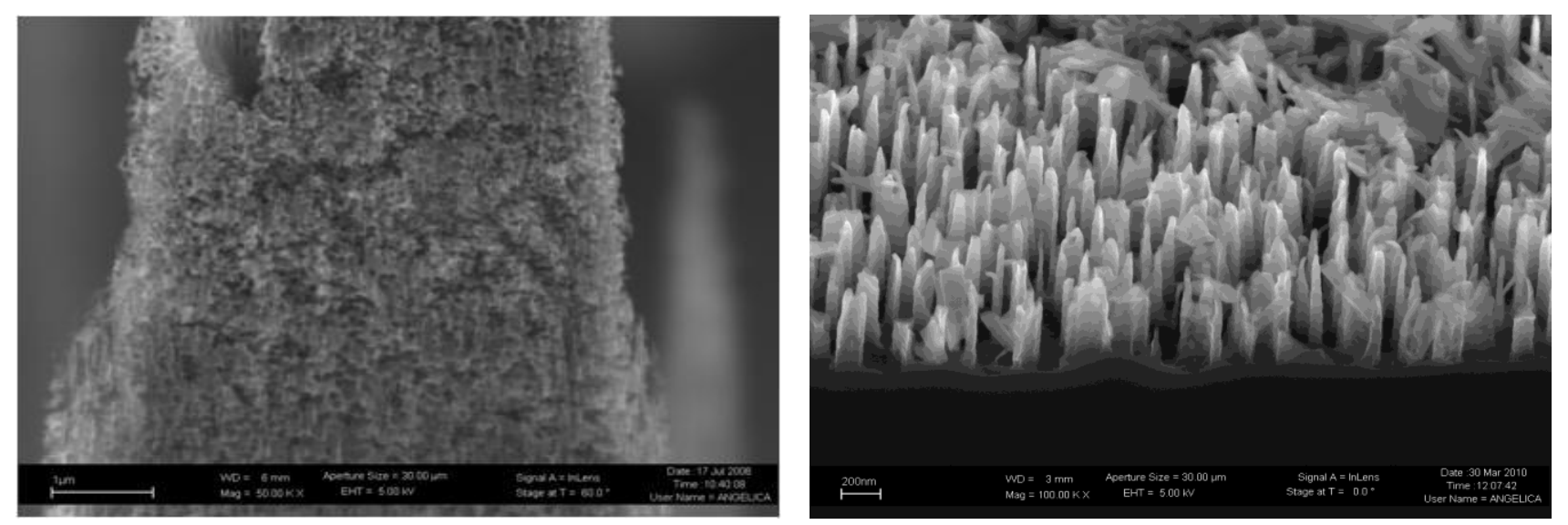

Figure 9. Nanostructured Si electrode obtained at Politecnico di Torino via the Black Silicon obtained by reactive ion etching (RIE) technology, described in [66].

It has been observed that protons accumulate at the anode and are consumed at the cathode faster than they are transported across the membrane and that MFC deprived of a membrane barrier are capable of higher power outputs [67]. In a traditional fuel cell the protons are the only ions present but in MFC and PMEC operating at neutral $\mathrm{pH}$ other cations, whose concentration can be several orders of magnitude higher than that of protons, compete with protons for migration across the membrane even if their mobility is lower. Quantification of a Nafion ${ }^{\circledR}$ membrane cation transport capability showed that cation species other than protons are primarily responsible for the transport of positive charges across the membrane and that this effect causes the increase in $\mathrm{pH}$ in the cathode compartment and the consequent decrease in efficiency of the MFC [68].

Another key area to be covered to make the PMEC technology a reality is the engineering of electron transfer pathways from/to the microorganisms and to/from the electrodes. Nevertheless, a power supply is needed to boost the voltage of the electrons because the standard potential of the electron donor (for example acetate $\mathrm{E}^{0}=-0.28 \mathrm{~V}$ ) is more positive than the one for hydrogen $\left(\mathrm{E}^{0}=-0.41 \mathrm{~V}\right.$ ). Furthermore, hydrogen generation at the cathode make use of noble metals like platinum to lower the over potential. 
There are many disadvantages to using platinum, including the high cost, the negative environmental impact of mining and the fact that chemicals such as sulphate, often present in the media, poison the platinum electrode.

Interfacing microbial metabolism with an electrode made of cheap material into a biocathode would represent an alternative to the use of noble metal. Furthermore, the tuning of the bacterial metabolism at both the anode, by wiring high energy electrons from PSI or ferredoxin and at the cathode, by connecting the electrogenic pathway of the microorganism to the hydrogenases, will reduce the need of an external power to boost the energy of the electrons improving the efficiency and sustainability of the device. To date only few examples of biocathodes developed for hydrogen production have been reported and none have been developed taking into account the electrogenic and metabolic pathways. In one case $D$. vulgaris immobilized on carbon electrodes was shown to produce hydrogen at the cathode in the presence of methyl viologen as external mediator [34]. With respect to the stability of operation a mediator-less microbial biocathode would be more desirable. Following these guidelines a hydrogen producing biocathode was constructed by taking into account the well-known reversibility of hydrogenases. On this basis an electrochemically active culture was developed by enriching a biofilm of hydrogen oxidizing bacteria on the anode and then reversing the polarity of the electrode so obtaining hydrogen production at the biocathode [35]. By using heterotrophic microorganism at the cathode we are changing the source of electrons from the organic substrate to the electrode. Therefore, to achieve high efficiencies with this approach we need to be able to connect the electron flow from the electrode directly into the protein machinery responsible for the hydrogen production. In strictly anaerobic microorganisms such as Clostridium spp. and Desulfovibrio spp. the electrons from pyruvate are transferred to ferredoxin and then to hydrogenase, that catalyze hydrogen formation. It is more advisable the use of Desulfovibrio vulgaris and Clostridium acetobutylicum as platforms where combining engineering of the electron transfer pathway with the hydrogen metabolism a high efficiency of hydrogen production is attained. $D$. vulgaris possess six hydrogenases. Four of these hydrogenases are located in the periplasm: hydAB (Fe-Fe), hynAB-1, hyn $A B-2(\mathrm{Ni}-\mathrm{Fe})$ and hysAB (Ni-Fe-Se); the other two are membrane bound and are facing the cytoplasm [21] (Figure 10).

By using genomic sequence and microarray technology it has been possible to identify the involvement of the different enzymes when different substrates were used as energy sources (hydrogen, pyruvate, thiosulphate) [69]. The study shown that the different hydrogenases have different sensitivity to oxygen. In particular, hyn $A B$ and hys $A B$ were up-regulated and involved in hydrogen oxidation while the membrane bound hydrogenases were overexpressed in response to hydrogen, with echABC able to function bi-directionally depending on the growth conditions [69]. This is in agreement with the observation that different cellular fraction showed electrochemical response on a carbon electrode when hydrogen was either oxidized or formed. In particular hydrogen oxidation was found to occur mainly when the periplasmic fraction was immobilized while hydrogen formation was equally occurring when either the periplasmic or the membrane fraction were immobilized [44]. Furthermore, a network of c-type cytochromes provides the electrical wiring between the different enzymes and they represent the perfect targets for integrating the extracellular electron transfer network with the hydrogen metabolism. Clostridium acetobutylicum is another good candidate as clostridia are the organisms principally responsible for hydrogen production in a mixed consortia of heterotrophic microorganisms prepared from poultries manure or sludge wastewater [70]. Furthermore, a megaplasmid-deficient mutant of Clostridium acetobutylicum ATCC 824 called M5 was 
created and tested [71]. This mutant lacks a megaplasmid responsible for butanol and acetone production. The yield of $\mathrm{H}_{2}$ production from this mutated strain was $47 \%$ higher than the parent wild type strain thanks to the genetic manipulation that allowed limiting the diversion of reducing equivalents to alternative metabolic pathways.

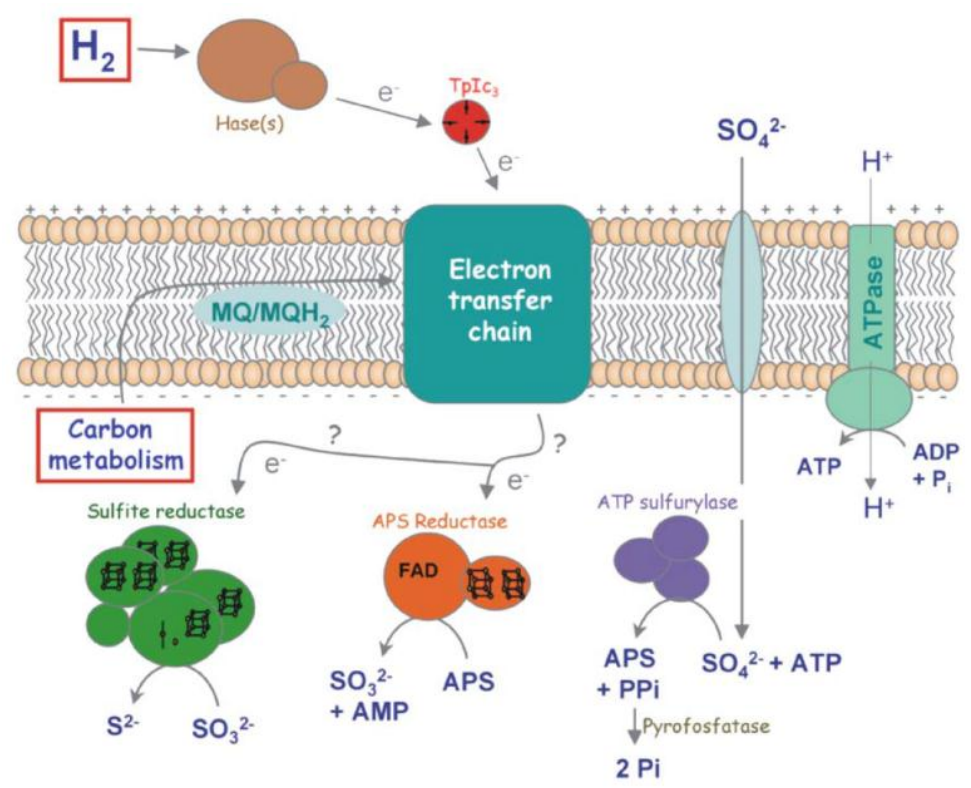

(a)

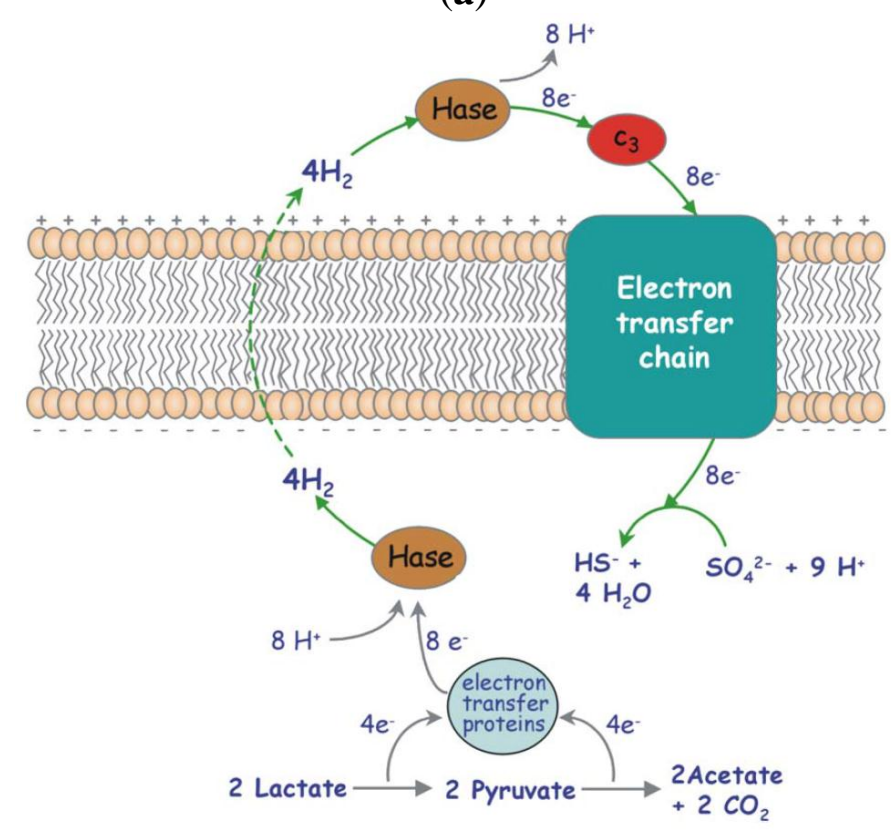

(b)

Figure 10. Network of redox proteins playing a role in the metabolism of Desulfovibrio vulgaris: (a) Schematic representation of the respiratory electron transfer chain in Desulfovibrio, with $\mathrm{H}_{2}$ or organic compounds as energy source and sulphate as terminal electron acceptor; (b) The hydrogen cycling mechanism to explain energy conservation in Desulfovibrio, while growing in lactate/sulphate [21]. 


\section{Integration of PMEC with Dark Anaerobic Fermentation}

A last field of challenges in the PMEC reactor lies in the integration with dark anaerobic fermentation as suggested in Figures 2 and 3. Among the major biological approaches to generate hydrogen, dark anaerobic fermentation of organic matter, which is a well-known process, represents a promising and environmental friendly process. Hence, it offers the possibility to achieve $\mathrm{H}_{2}$ generation using a wide variety of low-price renewable feedstock [72] and a suitable improvement of organic waste refuses treatments for many reasons:

- various organic wastes like agriculture residues, municipal and industrial wastewater, which have a negative value because they present disposal and treatment problems, can increase in value if converted to a high quality fuel;

- the contribution of greenhouse gases to the atmosphere is minimal owing to no fossil fuel input, both in the $\mathrm{H}_{2}$-production step and in the following utilization: $\mathrm{H}_{2}$ is the only carbon-free chemical fuel.

Hydrogen is an important intermediate in the microbial dominated degradation of organic material in anaerobic environments [73] and in conventional biogas plants it is utilized by hydrogenotrofic methanogens to produce methane (approximately $30 \%$ of $\mathrm{CH}_{4}$ produced).

To enhance the advantages of anaerobic digestion, either of energetic point of view or de-pollution benefits, two stages can be used by separating acidogenesis and methanogenesis process which lead to bioH $\mathrm{H}_{2}$ and bioCH${ }_{4}$ production, respectively [74]. During the natural process of anaerobic digestion, some bacteria convert the organic material present in the digester into hydrogen, carbon dioxide and watersoluble metabolites such as acetic acid, butyric acid, propionic acid and ethanol. Typically, these bacteria live in close proximity to methanogens that consume these metabolites, including hydrogen, producing their final products such as methane and $\mathrm{CO}_{2}$ according to the path outlined in Figure 11. The theoretical yields of hydrogen from dark fermentation depend largely on the type and consortium of anaerobic organisms that are used in the process.

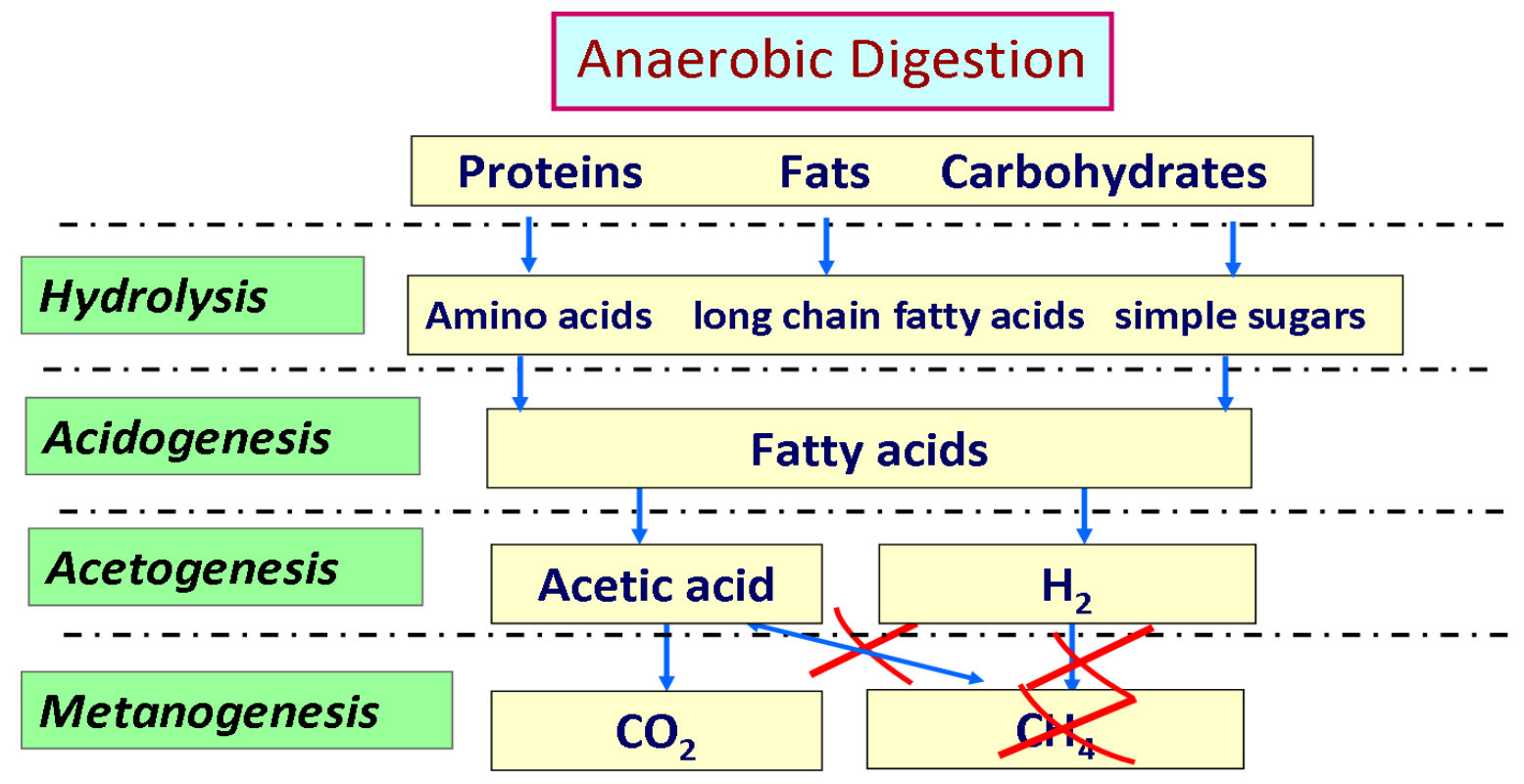

Figure 11. Overview of the metabolic pathway leading to the formation of hydrogen in anaerobic digestion process. 
Although glucose can theoretically provide $12 \mathrm{~mol}$ of hydrogen per mol glucose $\left(\mathrm{C}_{6} \mathrm{H}_{12} \mathrm{O}_{6}+6 \mathrm{H}_{2} \mathrm{O}\right.$ $\rightarrow 12 \mathrm{H}_{2}+6 \mathrm{CO}_{2}$ ), there are no metabolic pathways existing in Nature that would allow this, since cell growth would not be possible [75] and the reaction is not thermodynamically allowed $\left(\Delta \mathrm{G}^{\circ}=3.2 \mathrm{~kJ} / \mathrm{mol}\right)$. Facultative anaerobes evolve a maximum 2 or 4 mol of hydrogen from each mole of glucose consumed, when butyric or acetic pathways were followed [76]. Dark fermentation is promising for $\mathrm{bioH}_{2}$ processes due its low cost relatively high production efficiency, and stable $\mathrm{H}_{2}$ evolving enzymes [77,78]. [NiFe]-hydrogenases and $[\mathrm{FeFe}]$-hydrogenases can be utilized in dark fermentations by using a mixture of anaerobic microorganisms [79]. Since no $\mathrm{O}_{2}$ is produced or consumed in these reactions, both types of hydrogenases are less likely to be inactivated by oxygen. Organic wastes from agriculture or sewage can be fed into anaerobic reactors, combining waste management and $\mathrm{H}_{2}$ production [80,81]. Dark fermentations also solve the problem of expensive photo-bioreactors which are necessary for $\mathrm{H}_{2}$ production by either direct biophotolysis or photofermentations [78]. The bioreactors required for these dark fermentations can be kept simple and reduce production cost by lowering the amount of maintenance and area required to operate [77]. However, several reviews have identified obstacles, such as hydrogen consumption by uptake hydrogenases, substrate utilization, and overall low production yields due to inefficient metabolic pathways that limit the viable macro-scale production of hydrogen by dark fermentation [82,83]. Totally, starting fermentation by a mixed anaerobic including facultative bacterial population, various metabolic pathways can be simultaneously present during the $\mathrm{H}_{2}$ production. Figure 12 shows a number of alternative metabolic pathways. It is known that microorganisms of the genus Clostridium are very sensitive to the environmental conditions in which they live as consequence different metabolic routs could be followed. Depending on environmental conditions, acid production can be associated with $\mathrm{H}_{2}$ (acidogenesis with the production of volatile fatty acids VFA) or a concentration of alcohol and solvents with low $\mathrm{H}_{2}$ production (solventogenesis).

Nowadays, the exact way, which determines the transition from an acidogenic to an alcohol metabolism, is unknown, but studies have highlighted some parameters that influence the production of hydrogen, as $\mathrm{pH}$, temperature, nutrients and substrate, hydraulic retention time, redox potential, $\mathrm{H}_{2}$ partial pressure and mixing intensity $[84,85]$. Bacteria belong to Clostridium genus are mainly used for $\mathrm{H}_{2}$ production. They are obligate anaerobes, Gram positive bacteria with rod-shaped form. Clostridium have a substantial characteristics that distinguish them from other bacteria allowing $\mathrm{H}_{2}$ production under anaerobic conditions, instead of $\mathrm{CH}_{4}$ : they can produce endospores undergoing a process called sporulation, when they are exposed to unfavourable harsh environments, such as high temperature, ultraviolet radiations, presence of oxygen, extreme acidity and alkalinity, harmful chemicals like antibiotics and disinfectants, drying out, freezing and many other conditions that would easily kill a normal vegetative cell. Endospores are dormant bodies metabolically inactive, like seeds, which wait until the environment favors the growth of the bacterium. These endospores forming bacteria, mainly Clostridia and Bacilli, essentially have two phases to their life cycle, vegetative cells and endospores [86]. In extreme conditions, spores might be very resistant and they cannot be destroyed easily, as opposed to methanogens which have no such capability. Once environmental conditions improve, the endospores then germinate back into living vegetative cells that can grow and thrive. In fact, this happens that when the Clostridium spores are replaced in favorable conditions, with nutrients under anaerobic conditions, the germination and metabolism processes can start [87], consequently, hydrogen and the other metabolic products can be produced. 


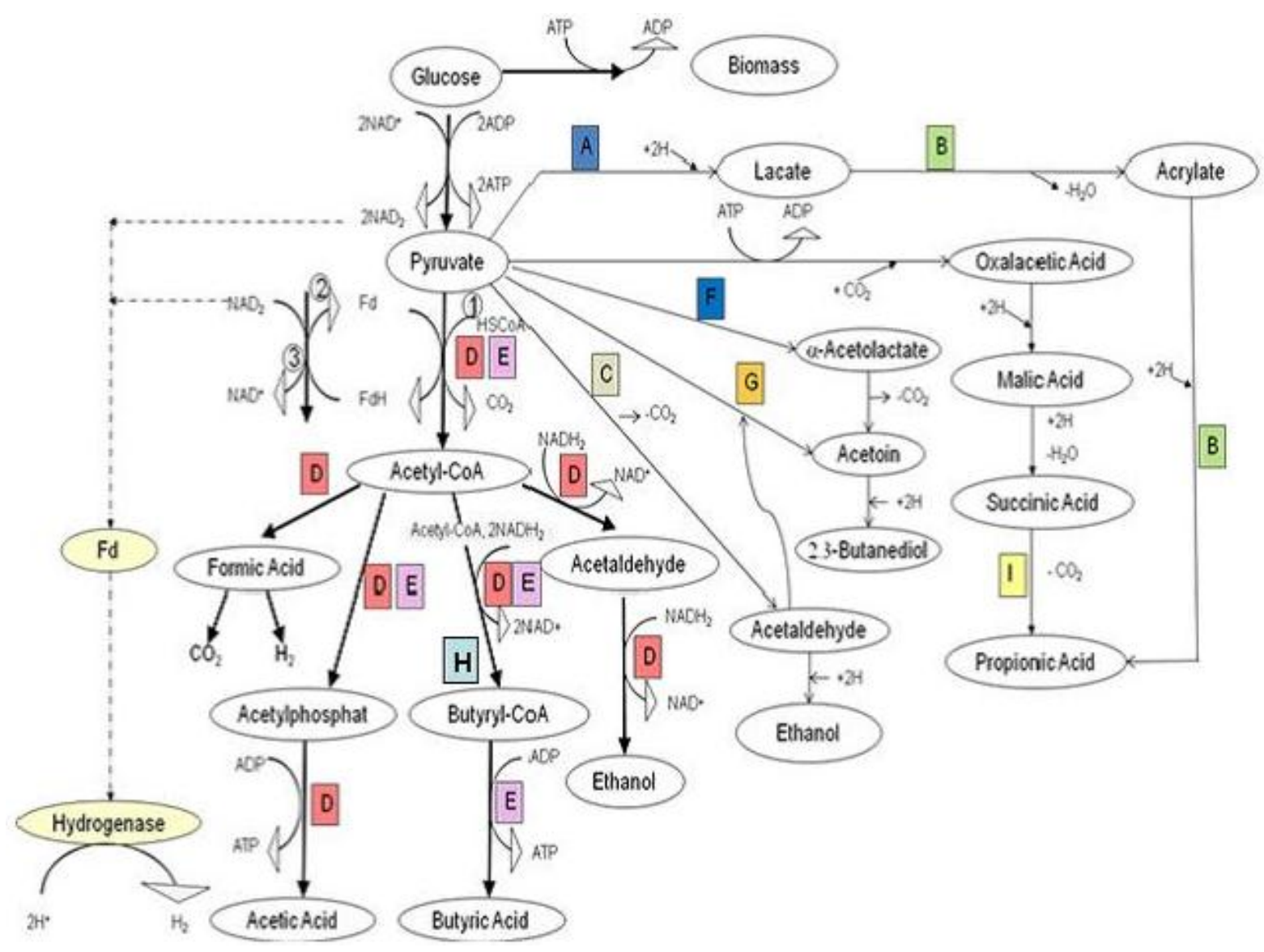

Figure 12. Metabolic pathway of glucose by HPB under anaerobic conditions. (1) Pyruvate: ferrodoxin oxidoreductase (PFOR); (2) Hydrogenase; (3) NADH: ferrodoxin oxidoreductase. Letters indicate organisms which conduct these reactions as follows: A, Lactic acid bacteria (Streptococcus, Lactobacillus); B, clostridium propionicum; C, Yeast, Acetobacter, Zymomonas, Sarcina ventriculi, Erwinia amylovora; D, Enterobacteriaceae (coli-aerogens); E, Clostridia; F, Aerobacter; G, Yeast; H, Clostridia (butyric, butylic organisms); I, Propionic acid bacteria [85].

In addition Clostridium spp. also Enterobacter spp. are $\mathrm{H}_{2}$-producing microorganisms with the advantage that are facultative bacteria able to grow in presence of oxygen. Based on phylogenetic analysis of the rDNA sequences of a mixture of hydrogen-producing bacteria, Fang et al. [88] found that $64.6 \%$ of all the clones were affiliated with three Clostridium species, $18.8 \%$ with Enterobacteriaceae and $3.1 \%$ with Streptococcus bovis (Streptococcaceae).

The remaining $13.5 \%$ belonged to eight operational taxonomic units, the affiliations of which were not identified. Methanogens play the vital ecological role in anaerobic environments of removing excess of hydrogen and of fermentation products that have been produced by acidogenic bacteria, producing methane. Methanogens are strict anaerobes [89] and when they are exposed to an aerobic environment, the oxygen lowers their adenylate charge and causes them to die [76]. The physiological differences between hydrogen producing bacteria (HPB) and hydrogen consuming bacteria (HCB) (methanogenic Archea) form the scientific rationale basis behind the development of the various methods proposed for preparation of hydrogen producing seeds [90]. The main differences between HPB and HCB are: 
- most methanogens are limited to a relatively narrow pH (about 7-8), while most HPB can grow over a broader $\mathrm{pH}$ range $(4.5 \div 7)$;

- HPB have growth kinetics much faster than methanogens (about 4-6 times);

- HCB differently than HPB are very sensitive to shear-stress because they are not able to sporulate.

Several pre-treatment methods, based on physiological differences between HPB and HCB, are applied on sewage sludge from various authors in order to select the first one [90]; in addition, during DF metabolism it is possible to continuously inhibit HCB activity by controlling several parameters, such as the $\mathrm{pH}$, the loading rate and the hydraulic retention time of the hydrogen producing bioreactor.

\section{Expected Impacts of the PMEC Technology}

Society today finds itself in the midst of a paradox: we need ever more energy to power our lives but strive to use less, on the understanding that currently we do not have limitless reserves. The anxiety around depletion of fossil fuels, their status as a precious resource and the associated concerns about the pollutants $\left(\mathrm{CO}_{2}\right)$ during exploitation and use, has precipitated a fervent race to find new, renewable sources of energy.

Looking towards nature we see there are only two clean fuels, hydrogen and electrons, both of which provide recurring sources of energy. Particularly attractive are solar technologies driven by the recognition that over 100,000 TW of solar energy falls on Earth every year, far in excess of our needs if it could be optimally captured and converted.

Another important challenge for society is the use of wastes as sources of energy, possibly accomplished via safe and environmental-friendly routes like those based on fermentation that may lead to enhanced energy production. Although anaerobic digestion for biogas production is a well- established technology scattered around in different countries, very little information is available on the geographical distribution of full-plant of dark fermentation for hydrogen production. This is because it is an emerging technology that still needs careful studies to understand the best and economic conditions to carry it out. The PMEC reactor technology here envisaged is based on a unique approach according to which these technologies are combined to the benefit of each other. A novel PMEC reactor concept based on photosynthetic and $\mathrm{H}_{2}$ generating bacteria connected to an artificial membrane-electrode assembly for the conversion of solar radiation into energy is combined with a dark fermentation unit based on bacterial strains to maximize hydrogen production from organic waste, with mutual exchange of heat, substrate and $\mathrm{CO}_{2}$.

The overall performance of the PMEC reactor must be tested at an overall production of at least $1 \mathrm{~kg} / \mathrm{day}$ of $\mathrm{H}_{2}$ derived in part from the treatment of waste organic like e.g., molasses, and in part from the direct exploitation of solar radiation. Alternative feed options for small scale units as those aimed at are domestic wastewater or refuse from local fruits and vegetables market [40]. More in general, wherever there is life and sun a potential application can be envisaged for the PMEC coupled with dark fermentation concept, spanning from cottages to skyscrapers, from farms to manned space vehicles, including revisiting the concept of domestic waste water treatment in dense populated cities, at the light of present technical suggestion. The flexibility and the modularity of the PMEC plants will enable easy adaptation of the technology to many fields, as hydrogen could be used for many purposes. It is expected that the two counterparts (PMEC reactor and DF) will have different intrinsic productivities in the combined system.

An indicative option PMEC reactor system for a proper geometrical matching into a single module would have $1 \mathrm{~m}^{2}$ of surface oriented Sun-ward, over a digester of about $1 \mathrm{~m}^{3}$ of capacity. If a tentative architecture 
of the PMEC unit is considered as in Figure 13, this would leave space for ancillary components (heat exchangers, $\mathrm{H}_{2}$ separator, and pumps) and eventually a MFC in another $1 / 2 \mathrm{~m}^{3}$ capacity underneath the PMEC reactor. These are just first approximation indicative dimensions taken as an example and that the full-scale PMEC sizes might be significantly different. Based on our laboratory practice as well as from literature evidences a conventional $1 \mathrm{~m}^{3}$ capacity digester fed with molasses can produce 4-6 $\mathrm{m}^{3}$ of hydrogen per day. For a hydrogen density of $0.0899 \mathrm{~kg} / \mathrm{m}^{3}$ this would imply a production of about $0.54 \mathrm{~kg} / \mathrm{day}$ at the most. By considering the strains highlighted above for the PMEC device, one could aim at achieving a specific hydrogen production rate of about $1 \mathrm{~kg} / \mathrm{day}$ overall goal [91].

External costs are heavy costs that society has to pay, very often hidden when advocating an apparently low-cost technology. These hidden costs come from environmental damages owing to the almost total dependence of petroleum to manufacture the "low cost technology" and the impact on the society (welfare spending for human diseases, air and soil contaminations, agriculture underproduction and last but not least, international tensions associated with security of energy supply). If we include external costs in the total costs of conventional fuel, the $\mathrm{bioH}_{2}$ production by PMEC plus DF, could provide a cost-competitive process and falls in line with efforts to create new advanced technologies for future energy production. In all cases, however, any state of art of technology must be subjected to a carefully economic analysis to judge its long term viability.

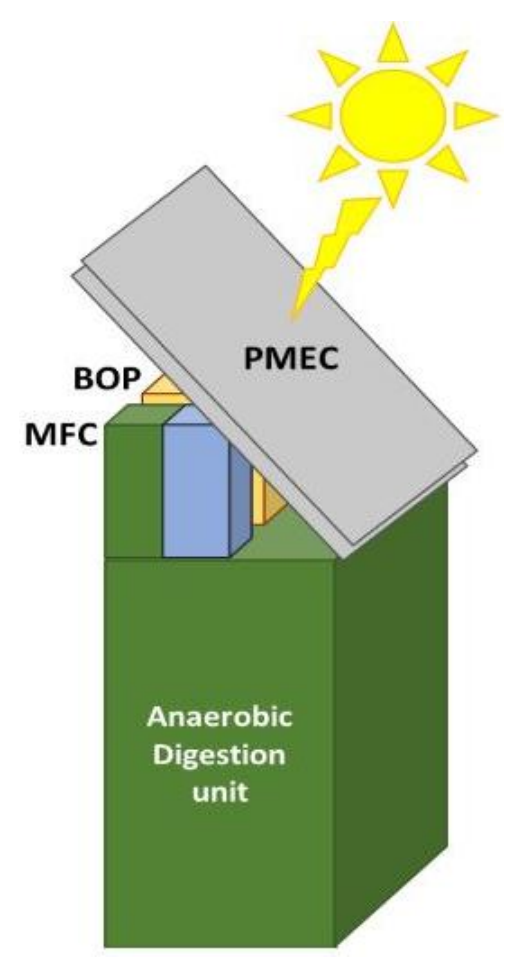

Figure 13. Tentative architecture of the PMEC unit.

Instead of cost analysis, in the case of energy producing technologies, the energy sustainability analysis is of fundamental importance. In this respect, the net energy calculations by Ruggeri [92] lead to the conclusion that dark fermentation for $\mathrm{H}_{2}$ production is not energetically sustainable unless for a bioreactor running in summertime and with a heat recovery of $50 \%$ of that spent to heat the mass at working temperature. Hence, there is a significant potential for the PMEC system by combining a thermal energy generating technology (PMEC reactor) and a heat depending technology, accomplished with the use of 
cheap means like natural convection or innovative heat exchanger designs (including, as an option, novel polymer heat exchangers).

Furthermore, during $\mathrm{H}_{2}$ dark fermentation from glucose only $1 / 3$ of the energy available is converted into $\mathrm{H}_{2}$, the others $2 / 3$ remains occluded in the form of VFA (propionate, butyrate, acetate, valerate etc.) and solvent (ethanol, butanol and acetone), reducing all possible hydrogen yields [74]. Since in any case these VFA have to be treated [93], the adoption of a MFC lead to an additional electric energy production which may assist the PMEC reactor or the balance-of-plant components (e.g., pumps, membrane for $\mathrm{CO}_{2} / \mathrm{H}_{2}$ separator etc.) improving the energy efficiency of whole system. The final effluents need to be treated by traditional technology in order to separate the solid part, which can be used as a fertilizer from the liquid, which could be used for carp breeding. Based on conservative mass and energy balances a $200 \mathrm{~L}$ MFC may be put in place, about $50 \mathrm{~W}$, which would be by far sufficient to boost the PMEC reactor operation, if needed.

However, it has to be underlined that the PMEC reactor technology drives energy from a nearly infinite source (the Sun) and has a highest "proximity" factor, whereas the organic wastes or biomasses have to be transported to the technology site with more or less high cost. The analysis of the energy sustainability needs to be performed by using two parameters: Energy Return of Investment (EROI) and Energy Payback Time (EPT) [94]. The evaluation of the two parameter permits to score the energy sustainability of such process. As plotted in Figure 14, the sustainability of dark fermentation is size dependent and for values about $1 \mathrm{~m}$ in diameter the EROI is around 5 (it is to note that present value of the EROI for oil is around 20). Our expectation, owing the contribution of the PMEC reactor, is to reach the value of 15 or higher [95]. These are values exceeding both the DF and the PMEC taken singularly.

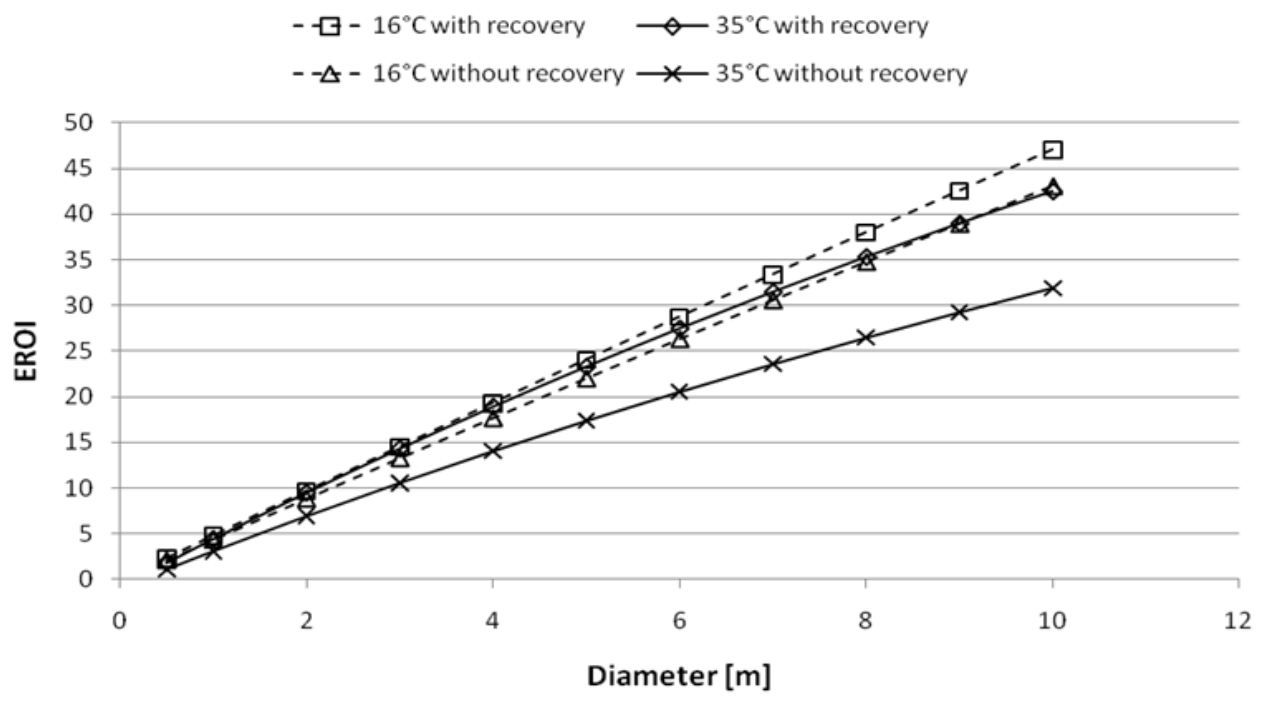

Figure 14. Energy Return on Investment of anaerobic digestion for $\mathrm{bioH}_{2}+\mathrm{CH}_{4}$ production; two situations were considered 16 and $35^{\circ} \mathrm{C}$ with and without heat recovery [96].

As mentioned above, additional advantages in terms of energy sustainability are expected by the combination of the two leading technologies of the PMEC concept. An additional advantage is that the $\mathrm{CO}_{2}$ obtained from the dark fermentation unit (nearly equal to the $\mathrm{H}_{2}$ produced) can be used to feed the cyanobacteria in an intensified way. Normally $\mathrm{CO}_{2}$ enrichment would favor increased photosynthetic activity but the present literature indicates $\mathrm{CO}_{2}$ depletion is a favorable condition for the formation of 
the cyanobacteria with extracellular micro "wires" and, clearly, experiments are required to optimize this balance.

\section{Conclusions}

In the present paper a critical review of the up-to-date technologies aimed at mimicking nature photosynthesis have been analyzed, highlighting merits and deficiencies. Particularly the state-of-art of photosynthetic microbial electrochemical cell (PMEC) for the production of hydrogen driven by solar power has been deemed to be able to provide renewable and carbon-neutral alternatives. This could be achieved by confining photoactive bacteria on the anode and heterotrophic bacteria confined on the cathode of a cell. This basic configuration today suffers from many technological problems such as: first, the low capture at the cathode of proton generated by photosynthetic bacteria at the anode, owing the low electrical potential difference naturally occurring between the bio-anode and bio-cathode; second the problem connected to the temperature control in the anode producing heat, which in turn is detrimental of the bacteria activity.

To overcome these bottlenecks an integrated system taking into account the advances in knowledge of DF producing hydrogen as well as that of Microbial Fuel Cell technologies have been envisaged and suggested. A new integrated technology able to integrate the performances of the three systems: PMEC, DF and MFC have been analyzed. As concerns the anaerobic digestion only the first acidogenic step will be utilized by separation of the natural ecology and metabolism of an anaerobic bacteria consortium into distinct classes: $\mathrm{H}_{2}$-forming bacteria (mainly Clostridium) and $\mathrm{H}_{2}$ consuming bacteria, hence an additional quantity of hydrogen is produced taking advantages of phase separation. The fermented liquid containing mainly volatile fatty acids, produced in the acidogenic reactor, will be used as cooling liquid of the PMEC to remove the heat generated by sun radiation, as integrated system. The heat recovery may reduce the necessary energy to keep the digester at about $35^{\circ} \mathrm{C}$. To increase the electrical potential in order to harvest more electrons at the cathode of PMEC a bias must be applied. The necessary electrical energy must be produced by utilizing the effluent from the dark fermentation containing volatile fatty acid, in the anode of a MFC. Lastly in order to utilize as much as possible the energy embedded in the organic refuse stream, the effluent of the MFC could be fed in a methanation reactor to produce methane and to meet the necessary water quality to fit with the necessary standards. In our opinion the envisaged system is highly stimulating even if many technological problems need to be solved, particularly the choice and the production of new materials either at the electrodes of PMEC and MFC. In this respect Life Cycle Analysis (LCA) Energy Return of Investment (EROI) approaches will be of helping not only in order to select the most suitable materials but mainly as research drive in order to judge step-by-step the choice towards the maximization of the energy production under form of hydrogen of the whole system and in the mean time to mitigate the impact towards the environment.

\section{Author Contributions}

Guido Saracco and Samir Bensaid coordinated the research theme on PMEC while Bernardo Ruggeri coordinated the research theme on AD and MFC of this paper. Guido Saracco, Samir Bensaid and Bernardo Ruggeri declare equal contribution in the writing the manuscript. All the authors read and approved the final manuscript. 


\section{Conflicts of Interest}

The authors declare no conflict of interest.

\section{References}

1. Nevin, K.P.; Richter, H.; Covalla, S.F.; Johnson, J.P.; Woodard, T.L.; Orloff, A.L.; Jia, H.; Zhang, M.; Lovley, D.R. Power output and columbic efficiencies from biofilms of Geobacter sulfurreducens comparable to mixed community microbial fuel cells. Environ. Microbiol. 2008, 10, 2505-2514.

2. Logan, B.E.; Call, D.; Cheng, S.; Hamelers, H.V.M.; Sleutels, T.H.J.A.; Jeremiasse, A.W.; Rozendal, R.A. Microbial electrolysis cells for high yield hydrogen gas production from organic matter. Environ. Sci. Technol. 2008, 42, 8630-8640.

3. Pant, D.; Arslan, D.; van Bogaert, G.; Alvarez Gallego, Y.; de Wever, H.; Diels, L.; Vanbroekhoven, K. Integrated conversion of food waste diluted with sewage into volatile fatty acids through fermentation and electricity through a fuel cell. Environ. Technol. 2013, 34, 1935-1945.

4. Logan, B.E.; Hamelers, B.; Rozendal, R.; Schröder, U.; Keller, J.; Freguia, S.; Aelterman, P.; Verstraete, W.; Rabaey, K. Microbial fuel cells: Methodology and technology. Environ. Sci. Technol. 2006, 40, 5181-5192.

5. Sharma, M.; Aryal, N.; Sarma, P.M.; Vanbroekhoven, K.; Lal, B.; Benetton, X.D.; Pant, D. Bioelectrocatalyzed reduction of acetic and butyric acids via direct electron transfer using a mixed culture of sulfate-reducers drives electrosynthesis of alcohols and acetone. Chem. Commun. 2013, 49, 6495-6497.

6. Wang, H.; Wang, G.; Ling, Y.; Qian, F.; Song, Y.; Lu, X.; Chen, S.; Tong, Y.; Li, Y. High power density microbial fuel cell with flexible 3D graphene-nickel foam as anode. Nanoscale 2013, 5, 10283-10290.

7. Hidalgo, D.; Tommasi, T.; Cauda, V.; Porro, S.; Chiodoni, A.; Bejtka, K.; Ruggeri, B. Streamlining of commercial Berl saddles: A new material to improve the performance of microbial fuel cells. Energy 2014, 71, 615-623.

8. De Schamphelaire, L.; Verstraete, W. Revival of the biological sunlight-to-biogas energy conversion system. Biotechnol. Bioeng. 2009, 103, 296-304.

9. Berk, R.S.; Canfield, J.H. Bioelectrochemical energy conversion. Appl. Environ. Miocrobiol. 1964, $12,10-12$.

10. Rosenbaum, M.; He, Z.; Angenent, L.T. Light energy to bioelectricity: Photosynthetic microbial fuel cells. Curr. Opin. Biotechnol. 2010, 21, 259-264.

11. Tanaka, K.; Tamamushi, R.; Ogawa, T. Bioelectrochemical fuel-cells operated by the cyanobacterium, Anabaena variabilis. J. Chem. Technol. Biotechnol. 1985, 35B, 191-197.

12. Rosenbaum, M.; Aulenta, F.; Villano, M.; Angenent, L.T. Cathodes as electron donors for microbial metabolism: Which extracellular electron transfer mechanisms are involved? Bioresour. Technol. 2011, 102, 324-333.

13. Yue, L.; Koichi, N.; Shoichi, M.; Yuki, T.; Hiroshi, I.; Tomohiro, K.; Kazuhiko, I.; Souichiro, K.; Kazuhito, H.; Shuji, N. Regulation of the cyanobacterial circadian clock by electrochemically controlled extracellular electron transfer. Angew. Chem. Int. Ed. 2014, 53, 2208-2211. 
14. Gorby, Y.A.; Yanina, S.; McLean, J.S.; Rosso, K.M.; Moyles, D.; Dohnalkova, A.; Beveridge, T.J.; Chang, I.S.; Kim, B.H.; Kim, K.S.; et al. Electrically conductive bacterial nanowires produced by Shewanella oneidensis strain MR-1 and other microorganisms. Proc. Natl. Acad. Sci. USA 2006, 103, 11358-11363.

15. Mao, L.; Verwoerd, W.S. Computational comparison of mediated current generation capacity of Chlamydomonas reinhardtii in photosynthetic and respiratory growth modes. J. Biosci. Bioeng. 2014, 118, 565-574.

16. Pisciotta, J.M.; Zou, Y.; Baskakov, I.V. Role of the photosynthetic electron transfer chain in electrogenic activity of cyanobacteria. Appl. Microbiol. Biotechnol. 2011, 91, 377-385.

17. Pagliano, C.; Saracco, G.; Barber, J. Structural, functional and auxiliary proteins of photosystem II. Photosynth. Res. 2013, 116, 167-188.

18. Ahmed, E.M.; Hegab, H.M.; Vanbroekhoven, K.; Pant, D. Techno-productive potential of photosynthetic microbial fuel cells through different configurations. Renew. Sustain. Energy Rev. 2014, 39, 617-627.

19. Geelhoed, J.S.; Hamelers, H.V.M.; Stams, A.J.M. Electricity-mediated biological hydrogen production. Curr. Opin. Microbiol. 2010, 13, 307-315.

20. Strycharz, S.M.; Woodard, T.L.; Johnson, J.P.; Nevin, K.P.; Sanford, R.A.; Loeffler, F.E.; Lovley, D.R. Graphite electrode as a sole electron donor for reductive dechlorination of tetrachlorethene by geobacter lovleyi. Appl. Environ. Microbiol. 2008, 74, 5943-5947.

21. Matias, P.M.; Pereira, I.A.C.; Soares, C.M.; Carrondo, M.A. Sulphate respiration from hydrogen in Desulfovibrio bacteria: a structural biology overview. Prog. Biophys. Mol. Biol. 2005, 89, 292-329.

22. Berger, A.; Newman, J. An integrated 1-dimensional model of a photoelectrochemical cell forwater splitting. J. Electrochem. Soc. 2014, 161, 3328-3340.

23. Potter, M.C. Electrical effects accompanying the decomposition of organic compounds. Proc. $R$. Soc. Lond. B 1911, 84, 260-276.

24. Lovley, D.R. Powering microbes with electricity: Direct electron transfer from electrodes to microbes. Environ. Microbiol. Rep. 2011, 3, 27-35.

25. Lovley, D.R.; Nevin, K.P. A shift in the current: New applications and concepts for microbe-electrode electron exchange. Curr. Opin. Biotechnol. 2011, 22, 441-448.

26. Rabaey, K.; Rozendal, R.A. Microbial electrosynthesis-Revisiting the electrical route for microbial production. Nat. Rev. Microbiol. 2010, 8, 706-716.

27. Erable, B.; Féron, D.; Bergel, A. Microbial catalysis of the oxygen reduction reaction for microbial fuel cells: A review. ChemSusChem 2012, 5, 975-987.

28. Chen, S.; Rotaru, A.E.; Liu, F.; Philips, J.; Woodard, T.L.; Nevin, K.P.; Lovley, D.R. Carbon cloth stimulates direct interspecies electron transfer in syntrophic co-cultures. Biores. Technol. 2014, 173, 82-86.

29. Geelhoed, J.S.; Stams, A.J. Electricity-assisted biological hydrogen production from acetate by Geobacter sulfurreducens. Environ. Sci. Technol. 2011, 45, 815-820.

30. Call, D.F.; Wagner, R.C.; Logan, B.E. Hydrogen production by geobacter species and a mixed consortium in a microbial electrolysis cell. Appl. Environ. Microbiol. 2009, 75, 7579-7587.

31. Cracknell, J.A.; Vincent, K.A.; Armstrong, F.A. Enzymes as working or inspirational electrocatalysts for fuel cells and electrolysis. Chem. Rev. 2008, 108, 2439-2461. 
32. Reguera, G.; Nevin, K.P.; Nicoll, J.S.; Covalla, S.F.; Woodard, T.L.; Lovley, D.R. Biofilm and nanowire production leads to increased current in Geobacter sulfurreducens fuel cells. Appl. Environ. Microbiol. 2006, 72, 7345-7348.

33. Lovley, D.R. The microbe electric: Conversion of organic matter to electricity. Curr. Opin. Biotechnol. 2008, 19, 564-571.

34. Holmes, D.E.; Chaudhuri, S.K.; Nevin, K.P.; Mehta, T.; Methé, B.A.; Liu, A.; Ward, J.E.; Woodard, T.L.; Webster, J.; Lovley, D.R. Microarray and genetic analysis of electron transfer to electrodes in Geobacter sulfurreducens. Environ. Microbiol. 2006, 8, 1805-1815.

35. Nevin, K.P.; Kim, B.C.; Glaven, R.H.; Johnson, J.P.; Woodard, T.L.; Methé, B.A.; Didonato, R.J.; Covalla, S.F.; Franks, A.E.; Liu, A.; Lovley, D.R. Anode biofilm transcriptomics reveals outer surface components essential for high density current production in Geobacter sulfurreducens fuel cells. PLoS One 2009, 4, e5628.

36. Inoue, K.; Leang, C.; Franks, A.E.; Woodard, T.L.; Nevin, K.P.; Lovley, D.R. Specific localization of the c-type cytochrome $\mathrm{OmcZ}$ at the anode surface in current-producing biofilms of Geobacter sulfurreducens. Environ. Microbiol. Rep. 2011, 3, 211-217.

37. Strycharz, S.M.; Glaven, R.H.; Coppi, M.V.; Gannon, S.M.; Perpetua, L.A.; Liu, A.; Nevin, K.P.; Lovley, D.R. Gene expression and deletion analysis of mechanisms for electron transfer from electrodes to Geobacter sulfurreducens. Bioelectrochemistry 2011, 80, 142-150.

38. Huang, L.; Regan, J.M.; Quan, X. Electron transfer mechanisms, new applications, and performance of biocathode microbial fuel cells. Bioresour. Technol. 2011, 102, 316-323.

39. Piepenbrink, K.H.; Maldarelli, G.A.; de la Peña, C.F.M.; Mulvey, G.L.; Snyder, G.A.; de Masi, L.; von Rosenvinge, E.C.; Günther, S.; Armstrong, G.D.; Donnenberg, M.S.; et al. Structure of clostridium difficile pilj exhibits unprecedented divergence from known type iv pilins. J. Biol. Chem. 2014, 289, 4334-4345.

40. Richter, H.; Nevin, K.P.; Jia, H.F.; Lowy, D.A.; Lovley, D.R.; Tender, L.M. Cyclic voltammetry of biofilms of wild type and mutant Geobacter sulfurreducens on fuel cell anodes indicates possible roles of OmcB, OmcZ, type IV pilj, and protons in extracellular electron transfer. Energy Environ. Sci. 2009, 2, 506-516.

41. Zhang, X.; Pant, D.; Zhang, F.; Liu, J.; Logan, B.E. Long-term performance of chemically and physically modified activated carbons in microbial fuel cell air-cathodes. Chem. Electro. Chem. 2014, 1, 1859-1866.

42. Dubey, G.P.; Ben-Yehuda, S. Intercellular nanotubes mediate bacterial communication. Cell 2011, $144,590-600$.

43. Lovley, D.R. Reach out and touch someone: Potential impact of DIET (direct interspecies energy transfer) on anaerobic biogeochemistry, bioremediation, and bioenergy. Rev. Environ. Sci. Biotechnol. 2011, 10, 101-105.

44. Lojou, E.; Durand, M.C.; Dolla, A.; Bianco, P. Hydrogenase activity control at Desulfovibrio vulgaris cell-coated carbon electrodes: Biochemical and chemical factors influencing the mediated bioelectrocatalysis. Electroanalysis 2002, 14, 913-922.

45. Rozendal, R.A.; Jeremiasse, A.W.; Hamelers, H.V.M.; Buisman, C.J. Hydrogen production with a microbial biocathode. Environ. Sci. Technol. 2008, 42, 629-634. 
46. Villano, M.; de Bonis, L.; Rossetti, S.; Aulenta, F.; Majone, M. Bioelectrochemical hydrogen production with hydrogenophilic dechlorinating bacteria as electrocatalytic agents. Bioresour. Technol. 2011, 102, 3193-3199.

47. Fan, Y.; Sharbrough, E.; Liu, H. Quantification of the internal resistance distribution of microbial fuel cells. Environ. Sci. Technol. 2008, 42, 8101-8107.

48. Clauwaert, P.; Aelterman, P.; Pham, T.H.; de Schamphelaire, L.; Carballa, M.; Rabaey, K.; Verstraete, W. Minimizing losses in bio-electrochemical systems: The road to applications. Appl. Microbiol. Biotechnol. 2008, 79, 901-913.

49. Barber, J. Photosynthetic energy conversion: Natural and artificial. Chem. Soc. Rev. 2009, 38, 185-196.

50. Cheng, S.; Liu, H.; Logan, B.E. Increased power generation in a continuous flow MFC with advective flow through the porous anode and reduced electrode spacing. Environ. Sci. Technol. 2006, 40, 2426-2432.

51. Devrim, Y. Fabrication and performance evaluationof hybrid membranebased on a sulfonated polyphenyl sulfone/phosphotungstic acid/silicafor proton exchange membrane fuel cell at low humidity conditions. Electrochim. Acta 2014, 146, 741-751.

52. Logan, B.E. Exoelectrogenic bacteria that power microbial fuel cells. Nat. Rev. Microbiol. 2009, 7 , 375-381.

53. Yang, Y.; Xu, M.; Guo, J.; Sun, G. Bacterial extracellular electron transfer in bioelectrochemical systems. Process Biochem. 2012, 47, 1707-1714.

54. Fricke, K.; Harnisch, F.; Shroder, U. On the use of cyclic voltammetry for the study of anodic electron transfer in microbial fuel cells. Energy Environ. Sci. 2008, 1, 144-147.

55. Yi, N.H.; Nevin, K.P.; Kim, B.C.; Franks, A.E.; Klimes, A.; Tender, L.M.; Lovley, D.R. Selection of a variant of Geobacter sulfurreducens with enhanced capacity for current production in microbial fuel cells. Biosens. Bioelectron. 2009, 24, 3498-3503.

56. Baliaev, A.S.; Saffarini, D.A.; McLaughlin, J.L.; Hunnicutt, D. MtrC, an outer membrane decahaem c cytochrome required for metal reduction in Shewanella putrefaciens MR-1. Mol. Microbiol. 2001, $39,722-730$.

57. Coursolle, D.; Baron, D.B.; Bond, D.R.; Gralnick, J.A. The Mtr respiratory pathway is essential for reducing flavins and electrodes in Shewanella oneidensis. J. Bacteriol. 2010, 192, 467-474.

58. Meiti, L.A.; Eggleston, C.M.; Colberg, P.J.S.; Khare, N.; Reardon, C.L.; Shi, L. Electrochemical interaction of Shewanella oneidensis MR-1 and its outer membrane cytochromes OmcA and MtrC with hematite electrodes. Geochim. Cosmochim. Acta 2009, 73, 5292-5307.

59. El-Naggar, M.; Gorby, Y.A.; Xia, W.; Nealson, K.H. The molecular density of states in bacterial nanowires. Biophys. J. 2008, 95, L10-L12.

60. Rabey, K.; Clauwaert, P.; Aelterman, P.; Verstraete, W. Tubular microbial fuel cells for efficient electricity generation. Environ. Sci. Technol. 2005, 39, 8077-8082.

61. Peng, L.; You, S.J.; Wang, J.W. Carbon nanotubes as electrode modifier promoting direct electron transfer from Shewanella oneidensis. Biosens. Bioelectr. 2010, 25, 1248-1251.

62. Mohanty, N.; Berry, V. Graphene-based single-bacterium resolution biodevice and DNA transistor: Interfacing graphene derivatives with nanoscale and microscale biocomponents. Nano Lett. 2008, $8,4469-4476$. 
63. Mauritz, K.A.; Moore, R.B. State of understanding of Nafion ${ }^{\circledR}$. Chem. Rev. 2004, 104, 4535-4585.

64. Roeder, J.; Silva, H.; Nunes, S.P.; Pires, A.T.N. Mixed conductive blends of SPEEK/PANI. Solid State Ion. 2005, 176, 1411-1417.

65. Roeder, J.; Zucolotto, V.; Shishatskiy, S.; Bertolino, J.R.; Nunes, S.P.; Pires, A.T.N. Mixed conductive membrane: Aniline polymerization in an acid SPEEK matrix. J. Membr. Sci. 2006, 279, 70-75.

66. Chan, C.K.; Peng, H.; Liu, G.; McIlwrath, K.; Zhang, X.F.; Huggins, R.A.; Cui, Y. High-performance lithium battery anodes using silicon nanowires. Nat. Nanotechnol. 2008, 3, 31-35.

67. Bourdakos, N.; Marsili, E.; Mahadevan, R. A defined co-culture of Geobacter sulfurreducens and Escherichia Coli in a membrane-less microbial fuel cell. Biotechnol. Bioeng. 2014, 111, 709-718.

68. Rozendal, R.A.; Hamelers, H.V.M.; Buisman, C.J.N. Effects of membrane cation transport on pH and microbial fuel cell performance. Environ. Sci. Technol. 2006, 40, 5206-5211.

69. Pereira, M.P.; He, Q.; Valente, F.M.; Xavier, A.V.; Zhou, J.; Pereira, I.A.; Louro, R.O. Energy metabolism in Desulfovibrio vulgaris Hildenborough: Insights from transcriptome analysis. Antoine van Leeuwenhoek 2008, 93, 347-362.

70. Tommasi, T.; Sassi, G.; Ruggeri, B. Acid pre-treatment of sewage anaerobic sludge to increase hydrogen producing bacteria HPB: Effectiveness and reproducibility. Water Sci. Technol. 2008, 58, 1623-1628.

71. Oh, S.E.; Zuo, Y.; Zhang, H.; Guiltinan, M.J.; Logan, B.E.; Regan, J.M. Hydrogen production by Clostridium acetobutylicum ATCC 824 and megaplasmid-deficient mutant M5 evaluated using a large headspace volume technique. Int. J. Hydrog. Energy 2009, 34, 9347-9353.

72. Levin, D.B.; Pitt, L.; Love, M. Biohydrogen production: Prospects and limitations to practical application. Int. J. Hydrog. Energy 2004, 29, 173-189.

73. Schink, B. Energetics of syntrophic cooperation in methanogenic degradation. Microbiol. Mol. Biol. Rev. 1997, 61, 262.

74. Ruggeri, B.; Tommasi, T.; Sanfilippo, S. BioH 2 \& BioCH4 through Anaerobic Digestion: From Research to Full-Scale Applications (Green Energy and Technology Series); Springer: Berlin/Heidelberg, Germany, 2015; ISBN:978-1-4471-6430-2.

75. Woodward, J.; Orr, M.; Cordray, K.; Greenbaum, E. Enzymatic production of biohydrogen. Nature 2000, 405, 1014-1015.

76. Ruggeri, B.; Tommasi, T.; Sassi, G. Experimental kinetics and dynamics of hydrogen production on glucose by hydrogen forming bacteria (HFB) culture. Int. J. Hydrog. Energy 2009, 34, 753-763.

77. Hallenbeck, P.C.; Benemann, J.R. Biological hydrogen production; fundamentals and limiting processes. Int. J. Hydrog. Energy 2002, 27, 1185-1193.

78. Zaborsky, O. Biohydrogen; Plenum Press: New York, NY, USA, 1998.

79. Hawkes, F.R.; Dinsdale, R.; Hawkes, D.L.; Hussy, I. Sustainable fermentative hydrogen production: Challenges for process optimisation. Int. J. Hydrog. Energy 2002, 27, 1339-1347.

80. Benemann, J. Hydrogen biotechnology: Progress and prospects. Nat. Biotechnol. 1996, 14, 1101-1103.

81. Chittibabu, G.; Nath, K.; Das, D. Feasibility studies on the fermentative hydrogen production by recombinant Escherichia coli BL-21. Process Biochem. 2006, 41, 682-688.

82. Das, D.; Veziroglu, T.N. Hydrogen production by biological processes: A survey of literature. Int. J. Hydrog. Energy 2001, 26, 13-28. 
83. Pinto, F.A.L.; Troshina, O.; Lindblad, P. A brief look at three decades of research on cyanobacterial hydrogen evolution. Int. J. Hydrog. Energy 2002, 27, 1209-1215.

84. Bailey, J.E.; Ollis, D.F. Biochemical Engineering Fundamentals, 2nd ed.; McGraw \& Hill Press: New York, NY, USA, 1986.

85. Tommasi, T. Anaerobic Biohydrogen Production: Experimental Evaluation of Design Bioreactor Parameters for Dark Biohydrogen Production Using Organic Wastes; LAP LAMBERT Academic Publishing: Saarbrucken, Germany, 2011.

86. Brock, T.D.; Madigan, M.T.; Martino, J.M.; Parker, J. Biology of Microrganisms; Prentice-Hall: New York, NY, USA, 1994.

87. Stanier, R.Y.; Ingraham, L.J.; Mark, L.; Wheelis, P.D.; Painter, P.R. The Microbial World; Prentice Hall College: Upper Saddle River, NJ, USA, 1986.

88. Fang, H.H.P.; Zhang, T.; Liu, H. Microbial diversity of a mesophilic hydrogen-producing sludge. Appl. Microbiol. Biotechnol. 2002, 58, 112-118.

89. Oremland, R.S. Biogeochemistry of methanogenic bacteria. In Biology of Anaerobic Microorganisms; Zehnder, A.J.B., Ed.; John Wiley \& Sons, Inc.: New York, NY, USA, 1988; pp. 641-705.

90. Zhu, H.; Béland, M. Evaluation of alternative methods of preparing hydrogen producing seeds from digested wastewater sludge. Int. J. Hydrog. Energy 2006, 31, 1980-1988.

91. SOLHYDROMICS FP7-Energy-2008-FETn. 227192-Nanodesigned electrochemical converter of solar energy into hydrogen hosting natural enzymes or their mimics. Available online: http://www.fch-ju.eu/sites/default/files/FCH\%20Programme\%20Review\%202011\%20-\%20project\% 20Solhydromics.pdf (accessed on 31 December 2014).

92. Ruggeri, B.; Tommasi, T.; Sassi, G. Energy balance of dark anaerobic fermentation as a tool for sustainability analysis. Int. J. Hydrog. Energy 2010, 35, 10202-10211.

93. Foglia, D.; Ljunggren, M.; Wukovits, W.; Friedl, A.; Zacchi, G.; Urbaniec, K.; Markowski, M. Integration studies on a two-stage fermentation process for the production of biohydrogen. J. Clean. Prod. 2010, 18, 572-580.

94. Ruggeri, B.; Sanfilippo, S.; Tommasi, T. Sustainability of $\left(\mathrm{H}_{2}+\mathrm{CH}_{4}\right)$ by anaerobic digestion via EROI approach and LCA evaluations. In Life Cycle Assessment of Renewable Energy Sources, Green Energy and Technology Series; Anoop, S., Deepak, P., Stig Irving, O., Eds.; Springer: New York, NY, USA, 2013; pp. 169-194.

95. Hall, C.A.S.; Klitgaard, K.A. Energy and the Wealth of Nations: Understanding the Biophysical Economy; Springer, New York, NY, USA, 2012; ISBN:978-1-4419-9397-7.

96. Ruggeri, B.; Sanfilippo, S.; Tommasi, T.; Fino, D. Process Energy Sustainability Evaluation trough a LCA Approach. In Chemical Engineering Transactions; Klemes, J.J., Varbanov, P.S., Lam, H.L., Eds.; Associazione Italiana Di Ingegneria Chimica (AIDIC): Milano, Italy, 2011; ISBN:978-88-95608-16-7.

(C) 2015 by the authors; licensee MDPI, Basel, Switzerland. This article is an open access article distributed under the terms and conditions of the Creative Commons Attribution license (http://creativecommons.org/licenses/by/4.0/). 